\title{
Trade and industrial structure with large firms and heterogeneity*
}

\author{
Eddy Bekkers \\ University of Linz \\ Joseph Francois \\ University of Linz \\ $\&$ CEPR (London)
}

\begin{abstract}
We develop a model of trade and firm heterogeneity in an oligopolistic setting. This setting generates key differences in terms of modelling setup, modelling predictions and welfare implications with respect to the existing literature on trade and firm heterogeneity. In terms of modelling setup our approach allows us to explore interaction between potentially large heterogeneous firms, in contrast to recent trade literature with heterogeneity and atomistic firms. We offer a solution for the integer problem inherent in small group models, based on stochastic dominance. The model generates testable predictions deviating from the benchmark firm heterogeneity model of Melitz (2003) in terms of the effect of trade liberalization on markups, market shares, the market price. We also derive predictions on the effect of distance and market size on the probability of zero trade flows and export prices. Our model features the possibility that welfare declines as a result of trade liberalization. The result in Brander and Krugman (1983), the benchmark model for trade under oligopoly, that welfare unambiguously rises with free entry and might decline without free entry due to increased cross-hauling is reversed. In a setting with heterogeneous instead of homogeneous firms, welfare might decline with free entry. A negative welfare effect without free entry can be ruled out if the firm size distribution is sufficiently dispersed.
\end{abstract}

Keywords: Endogenous market structure, Firm heterogeneity, Oligopoly and trade, Welfare effects of trade liberalization

JEL codes: L11, L13, F12

printdate: December 2012

${ }^{*}$ Thanks are due to participants in Tinbergen Institute, CEPR and JKU workshops and the ETSG annual meetings. We thank Carlo Altomonte, Andrei Levchenko, Charles van Marrewijk and Peter Neary for useful comments. Address for correspondence: Eddy Bekkers, Johannes Kepler University Linz, Department of Economics, Altenbergerstraße 69, A - 4040 Linz, AUSTRIA. email: eddybekkers@gmail.com 


\section{Trade and industrial structure with large firms and heterogeneity}

ABSTRACT: We develop a model of trade and firm heterogeneity in an oligopolistic setting. This setting generates key differences in terms of modelling setup, modelling predictions and welfare implications with respect to the existing literature on trade and firm heterogeneity. In terms of modelling setup our approach allows us to explore interaction between potentially large heterogeneous firms, in contrast to recent trade literature with heterogeneity and atomistic firms. We offer a solution for the integer problem inherent in small group models, based on stochastic dominance. The model generates testable predictions deviating from the benchmark firm heterogeneity model of Melitz (2003) in terms of the effect of trade liberalization on markups, market shares, the market price. We also derive predictions on the effect of distance and market size on the probability of zero trade flows and export prices. Our model features the possibility that welfare declines as a result of trade liberalization. The result in Brander and Krugman (1983), the benchmark model for trade under oligopoly, that welfare unambiguously rises with free entry and might decline without free entry due to increased cross-hauling is reversed. In a setting with heterogeneous instead of homogeneous firms, welfare might decline with free entry. A negative welfare effect without free entry can be ruled out if the firm size distribution is sufficiently dispersed.

keywords: Endogenous market structure, Firm heterogeneity, Oligopoly and trade, Welfare effects of trade liberalization

JEL codes: L11, L13, F12.

\section{Introduction}

The reallocation effects of trade are an important mechanism linking openness to productivity. Bernard and Jensen (2004) attribute almost half of the rise of manufacturing total factor productivity in the USA between 1983 and 1992 to reallocation effects linked to resources being shifted towards more productive and trade oriented firms. Episodes of liberalization in developing countries also show the importance of changes in firm composition effects. Given the strong message from the empirical literature on composition effects, a number of models of heterogeneous productivity have been put forward in the recent theoretical trade literature to help us better understand composition effects linked to trade. Melitz (2003) and Melitz and Ottaviano (2008) introduce heterogeneous productivity in a monopolistic competition framework with respectively CES-preferences and linear demand preferences, whereas Bernard, et al (2003) include heterogeneous productivity in a model with Bertrand competition. However, firm heterogeneity has not been examined under oligopoly with free entry. We do so here, demonstrating that such an approach has several advantages, in particular the possibility to model large firms.

Production and trade at industry level is typically dominated by a small number of very large firms. For example, from Table 1, the top four motor vehicle producers account for approximately 40 percent of global production, while at the detailed (5-digit NAICS) industry level, the top four firms in the U.S. often represent 40 percent to 60 percent of sales. In addition to high concentration, industrial structure and markups are sensitive to the degree of openness and market size (Hoekman and Kee (2007) and Hoekman, Kee and Olarreaga (2004)). Yet, while markets are dominated by large firms, and markups are varying, an important feature of the recent workhorse monopolistic competition models with heterogeneity of both Melitz (2003) and Melitz and Ottaviano (2008) is that firms are atomistic, while with Melitz-type models, markups are fixed. Indeed, though individual, atomistic firms exit in equilibrium and are replaced by new entering firms, this has no implications for the properties of the market 
equilibrium at an aggregate or industry level. This theoretical feature offers the analytical advantage of enabling the definition of a smooth entry and exit process following policy shocks that can be characterized entirely in terms of firm population aggregates. However, it hinges on the assumption that even large firms are actually small, relative to the market as a whole and in terms of their individual relevance for the decisions of other firms.

Table 1: Examples of Industrial Concentration

\begin{tabular}{l|l}
\hline NAICS 31-34: All Manufacturing & $\begin{array}{l}\text { top } 50 \text { firms have } 24.5 \% \text { of U.S: revenue } \\
\text { top } 4 \text { firms have } 61.2 \% \text { of U.S. revenue } \\
\text { NAICS 334: Computers and electronics }\end{array}$ \\
$\begin{array}{l}\text { NAICS 336: Transportation equipment manufacturing } \\
\text { top } 4 \text { firms have } 42.1 \% \text { of U.S. revenue } \\
\text { sector represents } 20 \% \text { of world merchandise trade }\end{array}$ \\
NAICS 336311: Carburetors, pistons, etc & $\begin{array}{l}\text { top } 4 \text { firms have } 65.7 \% \text { of U.S. revenue } \\
\text { top } 4 \text { firms have } 41.7 \% \text { of U.S. revenue }\end{array}$ \\
NAICS 51113: Book publishers: & top 4 firms have $29.5 \%$ of U.S. revenue \\
NAICS 52211: Commercial banking & top 4 firms have $75.8 \%$ of U.S. revenue \\
NAICS 522210 Credit card issuing: & top 4 firms have $53 \%$ of revenue \\
NAICS 4461101: Pharmacies and drug stores: & top 4 firms have $42 \%$ of global vehicle sales
\end{tabular}
note: U.S. data are from U.S. Census (2006), and are for 2002.

Trade data are for 2004, from COMTRADE.

Global motor vehicle production is for 2007, from industry sources.

In this paper we depart from the approach followed in the recent literature. Instead of relying on large group assumptions under monopolistic competition, we combine oligopoly and firm heterogeneity with free entry. Basic aspects of market structure - markups, industrial concentration, relative firm positions, and prices for domestic and export markets - are endogenous under this approach. Preferences are assumed to be CES across different sectors and within each sector firms produce a homogeneous good. ${ }^{12}$ Modelling large non-atomistic firms requires us to work with firms living only for one period to keep the model tractable. Also others who have modelled the role of large firms in international trade like Di Giovanni and Levchenko (2013) work with this assumption. Firms living for a single period is a limitation of our approach in comparison to Melitz (2003) where firms live for multiple periods, subject to an exogenous death probability in each period. Unlike Bernard, et al (2003) and Melitz and Ottaviano (2008), we do not actually need to assume a specific distribution of firms cost structures (productivity) to generate our core results. We focus on market structure and the role of large firms, guiding us in the choice of modelling setup. There is only one factor of production and when studying trade between two countries, we assume like Melitz (2003) that the two countries are equal. This implies that wages are equal. Also, we follow Neary (2009) in working with a continuum of sectors. This implies that deviations of sectoral profit from the paid sunk entry costs implied by the discrete number of firms are subject to the law of large numbers at the level of the economy. Whereas Neary (2009) focuses on heterogeneity across sectors, we focus on heterogeneity within sectors and remain agnostic about differences between sectors. Exploring the effect of market size, we will work with equal sectors.

Our model differs in three important ways from the benchmark model of firm heterogeneity, Melitz (2003): in terms of modelling setup, in terms of modelling predictions and in terms of

\footnotetext{
${ }^{1}$ We emphasize large non-atomistic firms, abstracting from product differentiation, so that we can isolate model properties linked to discrete numbers of firms. This is the standard approach in models of trade and oligopoly, as pointed out by Leahy and Neary (2011)

${ }^{2}$ The recent oligopoly and trade literature has avoided CES preferences. However, as most of world trade actually involves imports by firms of raw materials, semi-processed goods, and industrial inputs, we view CEStype preferences as better justified for representing derived demand given standard representations of CES-type production and cost functions. In addition, as Feenstra (2010) points out, the recent use of quadratic utility functions and an additively separable numeraire is best suited for partial equilibrium analysis.
} 
welfare effects of trade liberalization. First, in terms of modelling setup our model allows for large firms, whereas in Melitz (2003) all firms are atomistic. Modelling large firms requires a solution of the integer problem. With small group competition, we cannot expect entry to lead to zero expected profits, and the actual number of firms matters. We use stochastic dominance to solve the integer problem and this allows us to pinpoint the unique number of entrants that satisfy free entry. The integer problem has been a sticking point in the modelling of oligopoly with heterogeneous costs. ${ }^{3}$ Our solution method also enables comparative statics on changes in market size and trade costs. Such solution methods may also prove useful for other models of trade with small group competition and firm heterogeneity, such as small group versions of the workhorse monopolistic competition model of Melitz (2003).

Second, in terms of modelling predictions the oligopoly model developed here generates a set of novel results relative to Melitz (2003), which can also be confronted with the data. A first difference in predictions is that in our model aggregate variables like price and output vary endogenously as a result of varying productivity draws of individual firms. In Melitz (2003) the specific cost draws of entering firms and the death of individual firms do not affect the equilibrium values, because firms are atomistic. This implies that aggregate variables follow deterministic paths as pointed out by Hopenhayn (1992). Equilibrium values of aggregate variables in Melitz (2003) can vary as a result of exogenous shocks to aggregate variables like demand or productivity, the approach followed in Ghironi and Melitz (2005). The nonmarginal role of individual firms and thus the endogenous variation in aggregate variables in our approach comes at a price: to keep the model tractable we work with firms living for a single period like Di Giovanni and Levchenko (2013) who also model large firms. But like Di Giovanni and Levchenko (2013) our approach makes it possible to explain aggregate volatility as a result of variation at the firm level. A second difference in predictions is that in our model markups are variable, whereas markups are fixed in Melitz (2003). In particular, markups from domestic sales decline and markups from exporting sales rise with a decline in trade costs. This prediction can be confronted with the empirical evidence on changes in markups in response to trade liberalization. Tybout (2001) summarizes empirical work on trade liberalization finding that markups decline in response to increased import competition, lending support to the predictions of our model. A third difference in predictions is that in Melitz (2003) market shares of all firms change equally in response to changes in trade costs, whereas in our model small exporting firms gain more market share than big exporting firms and big domestic firms lose less market share than small domestic firms. Also, this prediction is empirically testable. A fourth difference in predictions is that the market price can both decrease and increase in response to trade liberalization in our model, whereas in Melitz (2003) prices always decline.

Fifth, predictions on the effects of trade costs (distance) and market size on the probability of zero trade flows and export prices differ from Melitz (2003) and its extension with quality heterogeneity in Baldwin and Harrigan (2010). In our model, the effect of a shorter distance between countries on the probability of zero trade flows and fob export prices is ambiguous. When the number of entrants in the importing country does not change with a shorter distance and when the number of entrants induced by a shorter distance decreases, the probability of zero trade flows declines. When the number of entrants due to a shorter distance rises, the effect is ambiguous. A larger market size of the importer country increases the probability of zero trade flows and increases the fob export price. In Melitz (2003) the probability of zero trade flows rises with distance and declines with a larger market size.

A third set of differences with respect to Melitz (2003) lies in the welfare effects of trade liberalization. In our model welfare can decrease as a result of trade liberalization, whereas in Melitz (2003) welfare effects are always positive. Our results also provide a heterogeneous firms

\footnotetext{
${ }^{3}$ Neary (2010) also addresses the integer problem in models of oligopoly with free entry, but proposes a different way to solve it. Using aggregative games, the discrete number of firms free entry condition can be approximated by the continuous number of firms equivalent conditional upon the existence of a so called lean outsider.
} 
extension of Brander and Krugman (1983), the benchmark model for trade under oligopoly. They have shown that the welfare effect of trade liberalization in an oligopoly setting with homogeneous firms is unambiguously positive with free entry, but can be negative without free entry when trade costs are reduced from a prohibitive level due to increased costs of crosshauling. We reverse this result by showing that trade liberalization can reduce welfare with free entry, whereas the negative welfare effect without free entry in Brander and Krugman (1983) does not appear when firms are heterogeneous and the sales distribution follows a power law. With free entry the result is driven by the exit of domestic firms in response to more competitive pressure as a result of lower trade costs and additional entry of exporting firms when trade costs decline. The result is due to the model setup with a discrete number of firms and cannot be generated in models with a continuum of firms: the exit of a domestic firm constitutes a discrete jump in the number of firms and as such drives up the market price and dominates the price decreasing effect of lower trade costs. ${ }^{4}$

Without free entry, we show that the welfare gain of lower prices always dominates the welfare costs of increased cross-hauling if the sales distribution is sufficiently dispersed, i.e. if it follows a power law. The reason is that the cost gains of the large exporting firms dominate the increased costs of cross hauling due to the reallocation of market shares from domestic firms to exporters under these conditions. Firm level studies show that firm size distributions follow a power law (Axtell (2001) and Di Giovanni and Levchenko (2013)).

Besides filling a gap in the firm heterogeneity literature, from the perspective of modelling setup, modelling predictions and welfare implications of trade liberalization, we also make a contribution to the oligopoly and trade literature. This literature starts with the paper by Brander and Krugman (1983), showing the possibility of two way trade and reciprocal dumping in a sector with homogeneous firms. Van Long and Soubeyran (1997) study a model with heterogeneous firms in a partial equilibrium setting without free entry. Their main innovation is to show that the Herfindahl index of concentration is related to the variance of marginal costs of the different firms with implications for optimal strategic trade policy. Neary (2009) shows how oligopoly can be modeled in a general equilibrium setting working with a continuum of sectors working with homogeneous firms. ${ }^{5}$ Our paper extends these works by studying firm heterogeneity under oligopoly with free entry in a basic general equilibrium setting. ${ }^{6}$

The paper is organized as follows. In Section 2 the basic model is mapped out. Section 3 goes into the effects of international trade without free entry (free exit), whereas section 4 discusses international trade with free entry. Section 5 concludes.

\footnotetext{
${ }^{4}$ The assumption of product homogeneity seems harmless for this result. In a model with product differentiation, one can expect the negative welfare effect of exit of domestic firms to be even larger, as consumers value different varieties. To draw this conclusion would require a different modeling setup with small group monopolistic competition and firm heterogeneity. We leave that to future work.

${ }^{5}$ Francois and Horn (2008) employ an oligopoly model in general equilibrium to study antitrust policy in open economies. Since the 1990s an oligopoly structure with homogeneous firms has been used in computable general equilibrium models (Francois and Roland-Holst (1997), Francois, Manchin, and Martin (forthcoming)).

${ }^{6}$ Related papers include Atkeson and Burstein (2008) and Van Long et al. (2011). Atkeson and Burstein (2008) explain pricing to the market in an oligopoly setting, where the toughness of competition affects firm's optimal markups. They focus on different questions, and have a setup without a free entry condition and derives results using simulations. Van Long et al. (2011) also address firm heterogeneity in an oligopoly model with free entry. However, their paper is focused on a very different set of issues - the interaction of trade and R\&D. In addition, they do not deal with the integer problem as they have atomistic firms. Due to differences in focus and setup (with atomistic firms), they do not identify possible negative welfare effects from trade liberalization.
} 


\section{The Model}

\subsection{Basic Properties}

This section lays out the basics of the model without trade (or identically for an integrated or single global economy without trade costs). Industrial concentration emerges endogenously as a function of the degree of firm heterogeneity and market size, while the relationship of concentration to price depends on the cost structure.

There is a continuum of sectors of mass 1 in the economy with an oligopolistic structure. With a continuum of sectors, the effect of a price change on demand through the price index is negligible for firms. There are $L$ equal agents each supplying 1 unit of labor, receiving wage income $w$ and receiving all possible profit income. We normalize the wage $w$ at 1 . Agents have identical CES preferences across sectors:

$$
U=\left(\int_{0}^{1} q_{j}^{\frac{\sigma-1}{\sigma}} d j\right)^{\frac{\sigma}{\sigma-1}}
$$

Market demand $q_{j}$ in sector $j$ is given by:

$$
q_{j}=\frac{Y P_{U}^{\sigma-1}}{p_{j}^{\sigma}}
$$

$Y$ is the endogenous income of all agents, the sum of labor $L$ and profit income $\Pi$. $P_{U}$ is the consumer price index:

$$
P_{U}=\left(\int_{0}^{1} p_{j}^{1-\sigma} d j\right)^{\frac{1}{1-\sigma}}
$$

As we focus on one Cournot sector, we drop the sector index $j$. Within each sector firms produce a homogeneous good. Productivity is heterogeneous. One unit of labor can be transformed into $1 / c_{i}$ units of $q_{i}$ for the $i$-th firm which has marginal cost of production $c_{i}$. There are no fixed costs of production. Therefore the cost function of firm $i$ is given by

$$
C_{i}\left(q_{i}\right)=c_{i} q_{i}
$$

There is Cournot competition between the different firms. So, firms maximize profits towards quantity supplied, taking the quantity supplied by other firms as given. Profit of firm $i$ is given by:

$$
\pi_{i}=p q_{i}-c_{i} q_{i}
$$

The first order condition is defined as:

$$
\frac{\partial \pi_{i}}{\partial q_{i}}=p\left[1-\frac{1}{\sigma} \frac{q_{i}}{q}\right]-c_{i}=0
$$

With $q=\sum_{i=1}^{n} q_{i} . n$ is the number of firms in the market. Using the first order condition, the second order condition can be written as follows (derivation in appendix A): ${ }^{7}$

$$
-\frac{1}{\sigma} \frac{p}{q}\left[\frac{(\sigma+1) c_{i}-(\sigma-1) p}{p}\right]<0
$$

\footnotetext{
${ }^{7}$ Reaction functions are stable whenever $\sigma>1 / 2$, as pointed out by Bandyopadhyay (1997), footnote 5 . With free entry, we have to allow for the possibility that 1 firm draws a very low cost and will be a monopolist, requiring $\sigma>1$ to satisfy the SOC. Therefore, $\sigma>1 / 2$ is a harmless assumption in our model.
} 
Using the definition for market share, $\theta_{i}=\frac{q_{i}}{q}$, the first order condition can be rewritten as:

$$
\begin{gathered}
p\left(1-\frac{\theta_{i}}{\sigma}\right)=c_{i} \\
\theta_{i}=\sigma \frac{p-c_{i}}{p}
\end{gathered}
$$

Only firms with $c_{i} \leq p$ supply a non-negative amount. We can define a cutoff cost level $c^{*}$ as the cost level with which a firm would just stay in the market. This cutoff cost level $c^{*}$ is equal or smaller than the market price $p$ :

$$
c^{*} \leq p
$$

The highest cost firm staying in the market has a cost level equal or just below the cutoff cost level and selling an amount just above zero. In the actual market equilibrium, the highest cost firm that can stay in the market can have a cost lower than $c^{*}$. This depends upon the specific sample of firms drawn from an initial cost distribution at a specific point in time. Hence, the market price can vary over time as a function of the actual firms entering. Still, the expression for the market price $p$ and total sales $q$ can be determined as a function of average costs $\bar{c}$ and the number of firms $n$. Combining the demand equation in (2) with $n$ first order conditions in equation (6) and with the equation for the sum of market shares, leads to the following solutions for the market price $p$, total sector sales $q$ and sales of an individual firm $q_{i}$ :

$$
\begin{gathered}
p=\frac{\sigma}{\sigma n-1} \sum_{i=1}^{n} c_{i}=\frac{\sigma n}{\sigma n-1} \bar{c} \\
q=\frac{Y P_{U}^{\sigma-1}}{\bar{c}^{\sigma}}\left(\frac{\sigma n-1}{\sigma n}\right)^{\sigma} \\
q_{i}=\sigma Y P_{U}^{\sigma-1} \frac{\frac{\sigma n}{\sigma n-1} \bar{c}-c_{i}}{\bar{c}^{\sigma+1}}\left(\frac{\sigma n-1}{\sigma n}\right)^{\sigma+1}
\end{gathered}
$$

with $\bar{c}$ the unweighted average cost of firms, $\bar{c}=\frac{1}{n} \sum_{i=1}^{n} c_{i}$.

Using equation (10), equation (11) can be rewritten to express the number of firms as a function of the cutoff cost level and average cost:

$$
n=\frac{1}{\sigma} \frac{\bar{m}}{\bar{m}-1} \leq \frac{1}{\sigma} \frac{c^{*}}{c^{*}-\bar{c}}
$$

With $\bar{m}$ a measure for average markup defined as price divided by unweighted average cost, $\bar{m}=p / \bar{c}$. On the basis of equation (14) we make the following observation:

Observation 1. The market structures and average markups of industries are related to the degree of heterogeneity. In particular, the lower the degree of cost heterogeneity, as measured by the difference between average cost $\bar{c}$ and the highest cost $c^{*}$, the more competitive the structure of the industry and the smaller the average markup.

Equation (14) shows that with the cost parameter of the highest cost firm being closer to average cost, there will be more firms in the market. Observation 1 highlights how the cost structure and the market structure in the model are interrelated. Industries where the cost levels of firms are closer to each other are more competitive with a larger number of firms. The reason is that in industries with more cost heterogeneity, firms have larger market shares, so there is space for less firms in the market. But the firms also display larger differences between price and marginal cost, so higher markups. ${ }^{8}$

\footnotetext{
${ }^{8}$ Working with a more restricted model without entry, Van Long and Soubeyran (1997) find similar results. They show that the variance of the cost distribution and the Herfindahl index of industry concentration are positively related in a model with Cournot competition: a larger variance leads to more industry concentration. From equation (14) above, it is clear that this result is more general, and holds with entry and exit as well.
} 


\section{$2.2 \quad$ Adding Free Entry}

We next introduce a mechanism for entry. The major change in this model relative to models with atomistic firms is that there is no unique set of steady state prices, output and firms. These vary as a function of the firms' cost draws. There is a unique number of entrant firms $n^{e}$, determined by a free entry condition. The number of entrants $n^{e}$ should be distinguished from the number of firms producing positive output, $n$. With the free entry condition, we can also determine the sign of the effect of a larger market and (later in the open economy) of lower trade costs upon the expected market price. Before proving that there is a unique number of entrants, we first show that a unique Nash equilibrium emerges for a given number of entrants $n^{e}$ and a given cost draw for the entering firms, as stated in the following proposition:

Proposition 1. For a given number of entrants $n^{e}$ and a given set of cost draws $\left\{c_{1}, c_{2}, \ldots, c_{n^{e}}\right\}$, a unique Nash equilibrium of number of producing firms, $n$, sales $\left\{q_{1}, q_{2}, \ldots, q_{n}\right\}$ and market price $p$ will emerge.

Proof. Rank the marginal cost draws from small to large as $c_{1} \leq c_{2} \leq \ldots \leq c_{n^{e}}$. Define $\widetilde{n}$ as the number of firms, such that with $\widetilde{n}$ producing firms all firms generate non-negative profits and with $\widetilde{n}+1$, at least one firm generates negative profits, formally expressed as:

$$
p_{\widetilde{n}} \geq c_{\widetilde{n}} ; p_{\widetilde{n}+1}<c_{\widetilde{n}+1}
$$

$p_{\widetilde{n}}$ is the market price when the $\widetilde{n}$ lowest cost firms are producing. The ranking of costs and market price $p$ non-increasing in the number of firms $n$ implies that $p_{\widetilde{n}-1} \geq c_{\widetilde{n}-1}$ and $p_{\widetilde{n}+2}<c_{\widetilde{n}+2}$ and thus the existence of a unique $\widetilde{n}$.

To show that $p$ is non-increasing in $n$, start from equation (11) and suppose that $\Delta n$ firms enter the market with average cost $\bar{c}_{j}$. This generates a change in price of:

$$
\begin{aligned}
\Delta p & =\frac{\sigma}{\sigma(n+\Delta n)-1}\left(\sum c_{i}+\bar{c}_{j}\right)-p \\
& =\frac{\sigma \Delta n}{\sigma(n+\Delta n)-1}\left(\bar{c}_{j}-p\right)
\end{aligned}
$$

$\Delta p<0$ when $\bar{c}_{j}<p$ and $\Delta p=0$ when $\bar{c}_{j}=p . \bar{c}_{j}>p$ is not possible, as $\Delta p<\bar{c}_{j}-p$ implying negative profits of the entering firms.

Uniqueness of the number of producing firms $\widetilde{n}$ implies trivially unique $\left\{q_{1}, q_{2}, \ldots, q_{n}\right\}$ and $p$ from equations (11) and (13).

$\widetilde{n}$ is the number of firms such that the highest cost firm can still produce profitably, whereas with $\widetilde{n}+1$ firms the highest cost firm could not make positive profits. $\bar{c}_{j}>p$ in the second part of the proof would mean the entry of a firm with marginal cost higher than the ruling market price. This is not possible, as the market price increases insufficiently for this firm to make positive profit.

Hence, for a given set of cost draws there is a unique market price $p$, a unique number of producing firms $n$ and the sales of each firm $q_{i}$ follows from equation (13). If costs would be deterministic, Proposition 1 would fully characterize sectoral equilibrium. In our model cost draws are stochastic. This implies a free entry condition (FE), which endogenizes the number of entrants $n^{e}$. Firms have to draw new production costs each period. This can be interpreted as firms making new production plans each year. This interpretation implies that firms also have to pay sunk entry costs and draw a new cost parameter each period.

Operationally, we assume that firms pay a sunk entry cost $f_{e}$ each period to draw a cost parameter $c$ randomly from a set of initial $\operatorname{costs} C$ with a certain discrete distribution of costs $F(c)$ with lower bound $\underline{c}$ and upper bound $\bar{c}$. Hence, uncertainty about productivity is a barrier to entry for firms. They start to produce when they can make positive operating profits. 
Production plans are good for only one period. Every period all producing firms have to pay again sunk entry costs to draw again from the cost distribution for plans for the next period. The sunk entry costs use labor. As free entry leads to almost zero expected profits, profit income is used on average to pay labor in the entry sector. Profit in a sector can deviate from the paid sunk entry costs, due to the stochastic nature of cost draws and due to the discrete number of firms. Therefore, we leave $Y$ under free entry unspecified until we look at the effect of a larger market size.

The FE leads to a unique number of entrants $n^{e}$ in the model. It is given by equalizing the ex ante expected profits from entry with the sunk entry cost. The FE expression is more complicated than in models with atomistic firms, like Melitz (2003) and Melitz and Ottaviano (2008). First, as the market price $p$ depends upon the marginal costs drawn, the expected profit is written as an expected value over the market price $p$ given the cost parameter drawn and the number of entrants, $j\left(p \mid c, n^{e}\right)$ and the cost distribution, $f(c)$. The distribution of $p$ is conditional upon the number of entering firms $n^{e}$, as the number of entering firms affects probability distribution of the market price. Second, the free entry condition will in general not hold exactly and is therefore written in inequality terms:

$$
\bar{\pi}\left(n^{e}+1\right) \leq f_{e} \leq \bar{\pi}\left(n^{e}\right)
$$

$\bar{\pi}$ is the profit unconditional upon entry. We can elaborate upon this FE as follows:

$$
\sum_{c \in C} \sum_{p \in M\left(c, n^{e}+1\right)} \pi(p, c) I[c \leq p] j\left(p \mid c, n^{e}+1\right) f(c) \leq f_{e} \leq \sum_{c \in C} \sum_{p \in M\left(c, n^{e}\right)} \pi(p, c) I[c \leq p] j\left(p \mid c, n^{e}\right) f(c)
$$

To express expected profit we sum over costs, $f(c)$ and over prices, conditional upon cost $c$ for one firm and number of entrants $n^{e}$, expressed by the conditional price density $j\left(p \mid c, n^{e}\right)$. Note that the density of costs $f(c)$ is independent of the number of entrants: the probability to draw a certain cost for an entrant is independent of the number of other entrants. $C$ is the set of initial costs and $M\left(c, n^{e}\right)$ is the set of all possible market prices when 1 firm has drawn cost $c$ and the number of entrants is $n^{e} . \pi(p, c)$ is the profit of a firm facing market price $p$ and having marginal cost $c$ in a single sector:

$$
\pi(p, c)=\sigma Y P_{u}^{\sigma-1} \frac{(p-c)^{2}}{p^{\sigma+1}} I[c \leq p]
$$

$I[c \leq p]$ is the probability that $c$ is smaller than $p$. It features in the $\mathrm{FE}$, as we sum over all possible cost draws. Therefore, we have to add that only firms with costs lower than the market price make positive profits.

Using the introduced notation, we can define an equilibrium in this economy as follows:

Definition 1. A free entry equilibrium consists for a given initial cost distribution $F(c)$ of a unique number of entrants $n^{e}$ and a varying number of actually producing firms $n$, sales $\left\{q_{1}, q_{2}, \ldots, q_{n}\right\}$ and market price $p$ as a function of the cost draws $\left\{c_{1}, c_{2}, \ldots, c_{n^{e}}\right\}$. $n^{e}$ is determined by the FE condition (16) and the corresponding expression for profit in equation (17). $n$ is determined by the ranking of the cost draws as described in the proof of proposition 1 and satisfaction of equation (15). $p$ and $\left\{q_{1}, q_{2}, \ldots, q_{n}\right\}$ are for given $n$ determined by equations (11) and (13) respectively.

The following proposition claims that the free entry condition generates a unique equilibrium for the number of entering firms $n^{e}$, i.e. a unique long run equilibrium. This means that while market indicators are stochastic (prices vary, as does supply), the number of firms "in the game" or active as entrants is uniquely determined by market conditions.

Proposition 2. There is a unique number of entering firms $n^{e}$ that leads to satisfaction of the free entry condition in equation (16). 
Proof. The proof proceeds in four steps. First, observe that the density function of costs conditional upon the number of entrants $n^{e}$ is independent of the number of entrants $n^{e}$. Second, first order stochastic dominance (FOSD) of the probability density function $J\left(p \mid c, n^{e}\right)$ over $J\left(p \mid c, n^{e}+1\right)$ for any $n^{e}$ and for any $c$ is shown. From the proof of Proposition 1 , the market price $p$ is non-increasing in the number of firms $n$. This implies that for any market price $p$ given $n^{e}$, the market price $z$ given $n^{e}+1$ is $z=p-x$ with $x$ having a distribution function with $I_{x}(0)=0$. This implies or any non-decreasing function $v: \mathbb{R} \rightarrow \mathbb{R}$ :

$$
\sum v(z) j\left(z \mid c, n^{e}+1\right)=\sum\left(\sum v(p-x) i(x)\right) j\left(p \mid c, n^{e}\right) \leq \sum v(p) j\left(p \mid c, n^{e}\right)
$$

Hence, $J\left(p \mid c, n^{e}\right)$ FOSD $J\left(p \mid c, n^{e}+1\right)$ for any level of $n^{e}$ and $c$.

Third, it is shown that $\pi(p, c)$ increases in $p$. Differentiating $\pi(p, c)$ in equation (17) with respect to $p$ gives $^{9}$ :

$$
d \pi=\frac{Y P_{u}^{\sigma-1}}{p^{\sigma}} \theta(c)\left(\frac{(\sigma+1) c-(\sigma-1) p}{p}\right) I[c \leq p] d p+\pi(p, c) d I[c \leq p]
$$

The first term in (18) is positive by the SOC in equation (7). The second term is nondecreasing in $d p$, as the probability to draw a $c$ smaller than $p$ rises with $p$. Fourth, FOSD of $J\left(p \mid c, n^{e}\right)$ over $J\left(p \mid c, n^{e}+1\right)$ implies that the expected value of any function rising in $p$ taken over the distribution function $J\left(p \mid c, n^{e}\right)$ is larger than the expected value over $J\left(p \mid c, n^{e}+1\right)$. So, the expected profit expression in equation (16) declines in $n^{e}$ and hence there is a unique $n^{e}$ that satisfies the FE.

The first step in the proof implies that the outer summation over the cost distribution $f(c)$ can be disregarded. FOSD in the second step implies that the distribution of prices $J$ shifts to the left with more entrants, i.e. lower prices get more probability mass. The fact that $p$ is non-increasing in $n$ means that the entry of one additional firm leads to an upward shift of the support of probability function $j\left(p \mid c, n^{e}\right)$. All points in the support of the probability function either do not change when the additional entering firm draws a cost higher than the ruling market price without this firm or the points in the support shift to the left when the entering firm draws a cost lower than the ruling market price.

In the third step it is shown that profit is increasing in market price. The first term on the LHS of equation (18) reflects two opposite forces. Firstly, a decline in the market price leads to larger market sales in the entire industry and thus a larger profit conditional upon entry. Secondly, a decline in market price decreases the profit margin (weighted by the market share $\theta$ ). This is due to a decline in the profit margin $p-c$ and to the declining market share. With a continuum of sectors, $Y$ and $P_{U}$ are not affected by changes in $p$ in a single sector. Below the effect of a larger market size $L$ is determined, affecting all sectors, so possible changes in $Y$ and $P_{U}$ then have to be taken into account.

\section{International Trade without Free Entry}

International trade is introduced in a setup with equal countries. We first explore the economy when there is no free entry in this section and add free entry in the next section. Without free entry firms can stop producing, so we can also call this a free exit approach. This no free entry (free exit) approach can be interpreted in two ways. First, we can consider it as a shortrun approach, where new firms do not come in yet to drive expected profits to zero. Second, it can be interpreted as an analysis of the effect of changes in variables like market size and trade costs, when these changes are sufficiently small that they do not induce any change in the

\footnotetext{
${ }^{9}$ As there is a continuum of sectors, the impact of market price on individual profit through aggregate profit in the whole economy is negligible.
} 
number of entering firms. As we work with a discrete number of firms, free entry conditions are expressed in terms of inequalities and sufficiently small changes in exogenous variables will possibly not change the number of entering firms. This section contains two subsections. The first subsection discusses several effects of changes in trade costs and the second subsection concentrates on welfare without free entry.

\subsection{Trade without Free Entry: Basics}

Before introducing trade, we explore the typical experiment in the trade literature of doubling the market size to mimic for the effects of a move from autarky to free trade. In the no-free-entry case the effect of an increase in market size is straightforward as pointed out in the following proposition:

Proposition 3. With all sectors equal, an increase in market size increases the sales of all firms proportionally in the no-free-entry case without a change in market price.

Proof. Rewrite equation (9) as follows:

$$
q_{i}=\sigma \frac{p-c_{i}}{p} \frac{(L+\Pi) P_{u}^{\sigma-1}}{p^{\sigma}}
$$

With a continuum of equal sectors with mass $1, L+\Pi$ is equal to (see Appendix B):

$$
L+\Pi=\frac{p}{\tilde{c}} L
$$

$\tilde{c}=\sum_{i=1}^{n} c_{i} \theta_{i}$ is the market share weighted average cost. From equation (9) and (11), $p$ and market share $\theta_{i}$ are not a function of $L$. So, $q_{i}$ rises proportionally in $L$.

Proposition 3 tells us that an increase in $L$ leads to a proportional increase in total income $L+\Pi$, a proportional increase in demand $q$ and also a proportional increase in production of each producer, $q_{i}$. The market price does not change, because the increased demand from a larger market is distributed proportionally across all firms in the market, so nothing changes in the competitive stance of the economy. Because profits also rise proportionally, adding a free entry condition will change the market price as a result of additional entry, as will be shown in the next section. ${ }^{1011}$

Lower trade costs do affect the market price, also without imposing a free entry condition. The reason is that the market price depends upon the costs of the firms in the market and they change when trade costs change. Lower trade costs lead to lower prices for the importing firms and this increases the degree of competition in the market. We now turn to a discussion of trade to show this point formally.

We introduce international trade between two countries $a, b=H, F$ with markets effectively segmented by trading costs. In particular we now introduce iceberg trade costs $\tau_{b a}$ in the Cournot sectors, meaning that marginal cost for delivery into country $a$ is increased at the rate $\tau$ relative to production and delivery for the domestic market $b$. There are no fixed or beachhead

\footnotetext{
${ }^{10}$ The effect of a uniform productivity rise across all firms and all sectors may also be of interest. From equation (11) the price $p$ declines proportionally with an increase in productivity (drop in costs $c$ ) for given number of firms $n$. From equation (2) market demand $q$ rises proportionally in all sectors $j$ if income $Y=L+\Pi$ stays constant. From equation (9) the market share $\theta_{i}$ stays constant and hence firm demand $q_{i}$ rises proportionally for all firms. From the profit expression in equation (17) the proportional drop in $c, p$ and $P_{U}$ implies that profit does not change. As a result the free entry condition does not change and the number of firms $n$ and total profit $\Pi$ stay constant.

${ }^{11}$ In our model demand is CES. Under linear demand, $q=(a-b p) L$ an increase in $L$ would neither affect market price, but an increase in $a$ (indicating individual willingness to pay) would lead to a higher price without free entry.
} 
trade costs, and the trading costs preclude return exports. We focus on the impact of increased globalization (i.e. falling trade costs).

The equilibrium market price in the representative Cournot sector becomes:

$$
p_{a}=\frac{\sigma n_{a}}{\sigma n_{a}-1} \bar{c}_{a}
$$

with $\bar{c}_{a}=\frac{1}{n_{a}}\left[\sum_{i=1}^{n_{d a}} c_{i d a}+\sum_{i=1}^{n_{x b}} \tau_{b a} c_{i x b}\right], n_{a}=n_{d a}+n_{x b}$ and $n_{d a}$ the number of domestic producing firms from country $a$ and $n_{x b}$ the number of exporting firms from country $b$. In equation (20), there is a direct effect of lower trade costs from country $b$ to country $a, \tau_{b a}$, on the market price: exporting firms have lower costs and therefore average costs decline. And there is an indirect effect, because firms producing for the domestic market can disappear and exporting firms can appear on the market. It can be shown that this indirect effect is 0 at the margin (see appendix B). The disappearing domestic firms and the appearing exporting firms have zero market share implying that their disappearance and appearance do not affect the market price. ${ }^{12}$ Log differentiating equation (20) with respect to $\tau_{b a}$ disregarding the effect through the number of firms $n_{a}$ gives the following expression for the relative change in the market price $p_{a}$ :

$$
\widehat{p}_{a}=\frac{\sum_{i=1}^{n_{x b}} \tau_{b a} c_{i x b}}{\sum_{i=1}^{n_{d a}} c_{i d a}+\sum_{i=1}^{n_{x b}} \tau_{b a} c_{i x b}} \widehat{\tau}_{b a}
$$

The elasticity of the market price with respect to trade costs, $\varepsilon_{p_{a}, \tau_{b a}}$, is between 0 and 1 :

$$
\varepsilon_{p_{a}, \tau_{b a}}=\frac{\sum_{i=1}^{n_{x b}} \tau_{b a} c_{i x b}}{\sum_{i=1}^{n_{d a}} c_{i d a}+\sum_{i=1}^{n_{x b}} \tau_{b a} c_{i x b}}
$$

From equations (21) and (22) we make the following observation:

Observation 2. Without imposing a free entry condition, a decline in trade cost $\tau_{b a}$ into country a leads to a lower market price $p_{a}$ in country $a$. The elasticity of the market price $p_{a}$ with respect to trade costs $\tau_{b a}$ is between 0 and 1 .

Equation (21) shows that a decline of trade costs $\tau$ drives down the market price less than proportional. The price is proportional to the average cost of firms in the market. As only the costs of the exporting firms are affected, the market price will change less than proportional. Observation 2 applies both to unilateral and bilateral liberalization.

Several other observations can be made on the effect of trade liberalization in the short run.

Observation 3. Some of the least productive firms are squeezed out of the market and more of the remaining firms export with a decline in trade cost $\tau$.

With a decrease in the market price, the domestic cutoff marginal cost also declines. How many firms are squeezed out of the market depends on the cost distribution of the firms, i.e. it depends on how far the highest cost firms are from the old market price.

More firms can enter the export market, as the exporting cutoff marginal cost rises when $\tau$ declines:

$$
\begin{gathered}
c_{x b}^{*}=\frac{p_{a}}{\tau_{a b}} \\
\widehat{c}_{x b}^{*}=\widehat{p}_{a}-\widehat{\tau}_{b a}=-\left(1-\varepsilon_{p_{a}, \tau_{b a}}\right) \widehat{\tau}_{b a}
\end{gathered}
$$

\footnotetext{
${ }^{12}$ As there are no fixed costs in the model (except the sunk entry costs), marginal firms have zero market share.
} 
Observation 4. For all firms in the market, markups from domestic sales decline and markups from exporting sales rise with a decline in trade cost $\tau$.

Markups of all domestic sales decline, as the costs of the firms remain equal, whereas the market price declines. Markups of the exporting firms rise with trade liberalization, as the effect of the declining trade costs dominates the effect of the decrease in market price in the exporting market. Using the letter $m$ to indicate markup, the latter can be shown formally:

$$
\begin{aligned}
m_{i x a} & =\frac{p_{b}}{\tau_{a b} c_{i x a}} \\
\widehat{m}_{i x a}=\widehat{p}_{b}-\widehat{\tau}_{a b} & =\left(\varepsilon_{p_{b}, \tau_{a b}}-1\right) \widehat{\tau}_{a b}
\end{aligned}
$$

The mechanism driving changes in markups is straightforward: lower trade costs lead to more competitive pressure as importing firms face lower marginal costs inclusive of trade costs. As a result markups from domestic sales decline. Markups from exporting sales rise, as the direct cost decrease (inclusive of trade costs) is larger than the decrease in the market price. The findings in observation 4 can be tested empirically, observing that in Melitz (2003) markups are fixed. Existing empirical evidence on markups and trade focus on changes in import competition. Tybout (2001) summarizes this work finding that domestic markups decline with increased import competition, which is in line with the predictions of our model.

As in most models of international trade firms increase their market share on the exporting market and their market share is reduced in domestic markets. But the relative gain and loss of exporters and domestic producers display an interesting pattern:

Observation 5. Large firms lose less market share on the domestic market than small firms and small exporting firms gain more market share on the export market than large exporting firms

Domestic and exporting market share are defined as:

$$
\begin{aligned}
\theta_{i d a} & =\sigma \frac{p_{a}-c}{p_{a}} \\
\theta_{i x a} & =\sigma \frac{p_{b}-\tau_{a b} c}{p_{b}}
\end{aligned}
$$

Observation 5 follows from totally differentiating the expressions for market shares in equations (27) and (28):

$$
\begin{aligned}
d \theta_{i d a} & =\sigma \frac{c_{i d a}}{p_{a}} \varepsilon_{p_{a}, \tau_{b a}} \widehat{\tau}_{b a} \\
\widehat{\theta}_{i d a} & =\frac{1}{\frac{p_{a}}{c_{i d a}}-1} \varepsilon_{p_{a}, \tau_{b a}} \widehat{\tau}_{b a} \\
d \theta_{i x a} & =\sigma \frac{c_{i x b}}{p_{b}}\left(\varepsilon_{p_{b}, \tau_{a b}}-1\right) \widehat{\tau}_{a b} \\
\widehat{\theta}_{i x a} & =\frac{1}{\frac{p_{b}}{c_{i x b}}-1}\left(\varepsilon_{p_{b}, \tau_{a b}}-1\right) \widehat{\tau}_{a b}
\end{aligned}
$$

Large exporting firms gain less market share than small exporting firms, because they hurt themselves more by raising their sales. Trade liberalization leads to lower marginal costs for exporting firms giving them an incentive to raise sales. But higher sales lead to a lower market price and this adverse effect works out stronger for big firms with more influence on the market 
price. So, big exporting firms adjust their sales less and thus gain less market share. For domestic firms the logic is identical. Big firms react less to the price drop than small firms. ${ }^{1314}$

The result in observation 5 is empirically testable using firm level data. It can be shown that in Melitz (2003) market share changes as a result of changes in trade costs are identical across firms in percentage terms, implying that in absolute terms big firms gain more (derivation in Appendix B). So, this provides a way to discriminate between Melitz (2003) and our model in terms of model predictions.

\subsection{Trade without Free Entry: Welfare}

Consider next the welfare effect of bilateral trade liberalization. We work with equal sectors. Welfare per worker is equal to:

$$
W=\frac{Y}{L P_{U}}=\frac{L+\Pi}{L P_{U}}
$$

Substituting equation (19), equation (33) can be written as:

$$
W=\frac{\frac{p}{\tilde{c}} L}{L P_{U}}=\frac{1}{\tilde{c}}
$$

$\tilde{c}$ are the market share weighted average costs, $\tilde{c}=\sum_{i=1}^{n_{d}} c_{i} \theta_{i d}+\sum_{i=1}^{n_{x}} \tau c_{i} \theta_{i x}$. Equation (34) makes clear that the welfare effect of lower trade costs depends upon the change in market share weighted average costs $\tilde{c}$. Elaborating on the change in $\tilde{c}$, using equation (9), the relative welfare change can be written as:

$$
\begin{gathered}
\hat{W}=-\widehat{\tilde{c}}=-\frac{1}{\tilde{c}}\left[\sum_{i=1}^{n_{d}} c_{i} \theta_{i d} \hat{\theta}_{i d}+\sum_{i=1}^{n_{x}} \tau c_{i} \theta_{i x} \hat{\theta}_{i x}+\sum_{i=1}^{n_{x}} \tau c_{i} \theta_{i x} \hat{\tau}\right] \\
\hat{W}=-\frac{1}{\tilde{c}}\left[\sum_{i=1}^{n_{d}} \sigma \frac{c_{i}^{2}}{p} \varepsilon_{p, \tau}-\sum_{i=1}^{n_{x}} \sigma \frac{\tau^{2} c_{i}^{2}}{p}\left(1-\varepsilon_{p, \tau}\right)+\sum_{i=1}^{n_{x}} \tau c_{i} \theta_{i x}\right] \hat{\tau}
\end{gathered}
$$

In both (35) and (36) the first term between brackets measures the cost decrease from the declining market share of domestic producing firms. The second term measures the cost increase from the rising market share of exporting firms. The third term measures the cost decrease from lower trade costs of exporting firms. We can make the following observation on the welfare effect of lower trade costs when the tariff is reduced from a prohibitive level:

Observation 6. The welfare effect of bilateral trade liberalization without free entry can be both positive and negative when the tariff is reduced from a prohibitive level, due to the increased costs of cross-hauling associated with the first units traded.

Brander and Krugman (1983) show that for homogeneous firms the welfare effects of trade liberalization reducing tariffs from a prohibitive level is negative. In Appendix B we prove with an example that the welfare effect of reducing tariffs from a prohibitive level can be both

\footnotetext{
${ }^{13}$ This set of results, related in particular to observation 5, has interesting political economy implications beyond the scope of this paper. As trade liberalization progresses, the dominant domestic firms gain relative domestic position (known as "standing" in the antidumping and trade safeguards literature). Assuming that lobbying efficiency is a function of industry concentration, increased concentration of firms with standing (i.e. the domestic industry) may increase their ability to organize and seek protection or relief against further drops in trade costs and foreign competition.

${ }^{14}$ Our results also imply that there is scope to extend the work by Bombardini (2008) on the political economy of trade protection with firm heterogeneity. She shows that the amount of trade protection is related to the size dispersion of industries, as big firms can more easily overcome the fixed lobbying costs. But her work does not address which firms are hurt most by trade liberalization and hence have the strongest incentives to lobby for protection, a question our oligopoly model can shed light on.
} 
positive and negative when firms are heterogeneous. With homogeneous firms as in Brander and Krugman (1983), reducing trade costs from the prohibitive level leads to entry of all foreign firms and the possible exit of domestic firms. So, there can be considerable increased welfare costs of cross-hauling. With heterogeneous firms, only some exporting firms enter, so the welfare costs from cross-hauling are smaller and the welfare effect can be both positive and negative. There is no ambiguity for negligible trade costs:

Observation 7. The welfare effect of bilateral trade liberalization without free entry is unambiguously positive when the tariff is negligible.

Observation 7 follows from equation (36). When the tariff is equal to 1 , the first two terms between brackets in equation (36) are equal (from equation (22) the elasticity $\varepsilon_{p, \tau, S R}$ is equal to $\frac{1}{2}$ in that case). So, only the third direct cost reducing term is left and therefore the welfare effect from trade liberalization is positive. Our result on the effect of trade liberalization when the tariff is negligible is in line with the result in Brander and Krugman (1983) for homogeneous firms. When the tariff is negligible there are no welfare losses due to increased cross-hauling, both with homogeneous firms and with heterogeneous firms. Instead, as we have seen in observation 6 , starting from prohibitive trade costs there can be considerable losses as a result of cross-hauling. Therefore, in this case the welfare effects under homogeneous firms and heterogeneous firms can differ, as with heterogeneous firms the welfare losses from cross-hauling are smaller with not all firms entering the exporting market at once.

Brander and Krugman (1983) only derive the welfare effects of trade liberalization when the tariff is either prohibitive or negligible. In the present heterogeneous productivity model, we can also determine the welfare effect for intermediate levels of trade costs. We define $\bar{c}_{O}$ and $s_{c}^{2}$ as the unweighted mean and variance of marginal costs in the open economy, analogous to the unweighted average of $\operatorname{costs} \bar{c}$ in the closed economy: ${ }^{15}$

$$
\begin{aligned}
\bar{c}_{O} & =\frac{1}{n}\left[\sum_{i=1}^{n_{d}} c_{i}+\sum_{i=1}^{n_{x}} \tau c_{i}\right] \\
s_{c}^{2} & =\frac{1}{n-1}\left(\sum_{i=1}^{n_{d}} c_{i}^{2}+\sum_{i=1}^{n_{x}} \tau^{2} c_{i}^{2}-n \bar{c}_{O}^{2}\right) .
\end{aligned}
$$

We can now state the following proposition:

Proposition 4. The welfare effect of bilateral trade liberalization without free entry is unambiguously positive: (i) if all exporting firms have marginal costs inclusive of trade costs $\tau c_{i}$ lower than the average of market price $p$ and average costs $\bar{c}_{O}$; (ii) if the coefficient of variation of costs, $\frac{s_{c}}{\bar{c}_{O}}$, is larger than the square root of $\frac{n}{n-1} \frac{1}{\sigma n-1}$

Proof. In Appendix B.

The first part of Proposition 4 tells us that if the exporting firms are productive enough, their gain in market share at the expense of domestic producing firms represents a welfare gain. More productive firms replace less productive firms. But when the exporting firms' marginal costs inclusive of trade costs are larger than the marginal costs of the domestic producing firms, the shift in market share towards exporting firms can represent a loss. This loss can be larger than the welfare gain due to lower trade costs.

To interpret the second part of Proposition 4 we start from equation (35), showing the three components of the welfare effects of changed trade costs, the gain from lower market shares of domestic firms, the loss from higher market shares of exporting firms and the direct cost gain of lower trade costs. Also, from observation 5 we know that the largest change in market share

\footnotetext{
${ }^{15}$ We divide by $n-1$ for the variance to get an unbiased estimator of the population variance of costs.
} 
occurs for firms with small market shares, domestic producing or exporting. When the variance of firms' costs is small, the share of exporting firms with small market shares, increasing their market shares most, is large. So, the welfare loss of rising market shares of relatively inefficient exporting firms (increased cross-hauling) is relatively large. If the variance of firms' costs is larger, there are not so many exporting firms at the margin of exporting, so the increased costs of cross-hauling are dominated by the direct cost gain of lower trade costs.

We can extend the second part of Proposition 4 relating marginal costs $c_{i}$ with revenues (firm size) $r_{i}=p q_{i}$. Defining $\bar{r}$ and $s_{r}^{2}$ as the unweighted mean and variance of revenues in the open economy, analogous to the definitions for costs, $\bar{r}=\frac{1}{n}\left[\sum_{i=1}^{n_{d}} r_{i d}+\sum_{i=1}^{n_{x}} r_{i x}\right]$ and $s_{r}^{2}=$ $\frac{1}{n-1}\left(\sum_{i=1}^{n_{d}} r_{i d}^{2}+\sum_{i=1}^{n_{x}} r_{i x}^{2}-n \bar{r}^{2}\right)$, we can state the following result:

Proposition 5. The welfare effect of bilateral trade liberalization without free entry is unambiguously positive if the coefficient of variation of revenues, $\frac{s_{r}}{\bar{r}}$, is larger than the square root of $\frac{n}{n-1} \sigma n-1$.

Proof. From equations (9) and (11) we get $r_{i}=\sigma\left(\frac{\sigma n}{\sigma n-1} \bar{c}_{O}-c_{i}\right) q$. This implies $\bar{r}=(\sigma q) \frac{\bar{c} O}{\sigma n-1}$ and $s_{r}^{2}=(\sigma q)^{2} s_{c}^{2}$. The result then follows from Proposition 4(ii).

We know from firm level studies (Axtell (2001), Di Giovanni and Levchenko (2013)) that firm size distributions follow a power law, i.e. they can be described by a Pareto distribution with a shape parameter close to 1 . So, the distribution is such that large firms dominate the market. Distributions following a power law with a shape parameter larger than 1 and smaller than 2 display an infinite variance and a finite mean. Therefore, the coefficient of variation tends to infinity. This implies that the condition in Proposition 5 is always satisfied: trade liberalization always has positive welfare effects without free entry. So, in our model the extension of Brander and Krugman (1983) to a setting with heterogeneous firms eliminates the possibility that harmful cross hauling dominates the positive effects from trade liberalization if the sales distribution follows a power law. This is an important result pointing out that the possibility of welfare losses from trade liberalization due to cross hauling identified by Brander and Krugman (1983) is not possible for a realistic firm size distribution.

The intuition for our result is straightforward: when large firms dominate the market the direct cost gains for large exporters outweigh the welfare loss from increased cross hauling as a result of increased trade. Under granularity high cost exporters picking up market share at the expense of domestic firms thereby harming welfare only play a marginal role. ${ }^{1617}$ Our result is in line with the empirical study on reciprocal dumping by Friberg and Ganslandt (2006) who do not find evidence that banning imports in the Swedish mineral water market would raise welfare.

\footnotetext{
${ }^{16}$ In equation (35) the first and second term represent respectively the decreased market share of domestic firms and increased market share of exporting firms. The last term represents the cost decrease for exporters. Under granularity the gain in the last term dominates the loss in the first two terms.

${ }^{17}$ The decreased market share of exporters in the current model without free entry should be distinguished from the beneficial reallocation effect towards exporters in Melitz (2003). A possible harmful effect of increased market shares of exporters seems contrary to the beneficial reallocation effect of market shares towards exporters in Melitz (2003). But the latter reallocation effect is driven by a free entry condition, where additional entry as a result of larger export opportunities drives up demand for labor resources raising the real wage and thus welfare. The analysis in this section does not include a free entry condition. The changes in domestic and exporting market shares represent mechanical changes used to explain how the variance of the cost distribution and granularity of the firm size distribution determine the welfare effect of increased cross-hauling.
} 


\section{International Trade with Free Entry}

\subsection{Trade with Free Entry: Basics}

Like in the previous section, before characterizing the two country model we first analyse the effect of an increase in market size $L$, as an indicator for the effect of a move from autarky to free trade. We define the expected market price $E p$ as an expectation over the price distribution:

$$
E p=\sum_{c \in C} \sum_{p \in M\left(c, n^{e}\right)} p j\left(p \mid c, n^{e}\right) f(c)
$$

Also, we express income $Y$ as the sum of labor income equal to the number of workers $L$ and profit income $\Pi=n^{e} \bar{\pi}$ net of entry costs, $n^{e} f_{e}:^{18}$

$$
Y=L+n^{e}\left(\bar{\pi}-f_{e}\right)
$$

We have the following result based upon the closed economy free entry condition as displayed in equation (16):

Proposition 6. With equal sectors a larger market size L leads to a lower average market price Ep under free entry, if the change in market size is large enough.

There are four steps to the proof. First, it follows from equation (17) and (40) that $\pi(p, c)$ is rising in $L$. Hence, for a sufficiently large change in $L$, the FE in equation (16) will be violated and $n^{e}$ has to adjust. Second, it has to be shown that $\pi(p, c)$ rises in $p$ if $p$ changes in all sectors. We first differentiate $\pi(p, c)$ with respect to $p$ substituting equation (40) for $Y$ and $P_{U}=p$ :

$$
\begin{aligned}
& d \pi=\sigma \frac{(p-c)^{2}}{p^{2}} I[c \leq p] n^{e} d \bar{\pi}+\sigma Y \frac{2 p^{2}(p-c)-2 p(p-c)^{2}}{p^{4}} I[c \leq p] d p+\pi(p, c) d I[c \leq p] \\
& d \pi=\sigma \frac{(p-c)^{2}}{p^{2}} I[c \leq p] n^{e} d \bar{\pi}+\sigma Y \frac{2 c(p-c)}{p^{3}} d p+\pi(p, c) d I[c \leq p]
\end{aligned}
$$

As $d I[c \leq p]$ (see proof of Proposition 2) and $d \bar{\pi}$ (proof in Appendix C) are both nondecreasing in $d p, \pi(p, c)$ rises in $p$. Third, FOSD of the probability density function $J\left(p \mid c, n^{e}\right)$ over $J\left(p \mid c, n^{e}+1\right)$ and $\pi(p, c)$ rising in $p$ implies that $n^{e}$ has to increase to restore the free entry condition in equation (16) after an increase in $L$. Fourth, a larger $n^{e}$ as a result of a larger $L$ and FOSD of $j\left(p \mid c, n^{e}\right)$ over $j\left(p \mid c, n^{e}+1\right)$ implies that $E p$ declines in $L$.

As a larger market size affects all sectors, we had to show that profit is rising in $p$ with aggregate profit income $\Pi$ and the price index $P_{U}$ treated as an endogenous variable, in contrast to the proof of uniqueness of sectoral equilibrium. As all sectors are equal, we could use $\Pi=n^{e} \bar{\pi}$ and $P_{U}=p$. Whereas a larger market size did not affect the market price without free entry, it does with free entry. The reason is straightforward. A larger market size enables all firms to expand their sales to expand proportionally. As a result profits rise. This causes additional entry, which drives down the market price.

Now we turn to the definition of equilibrium in a model with trade between two countries with index $a=H, F$. The equilibrium is based on the combined ZCP and FE conditions.

There are two ZCPs for domestic and exporting sales of firms in country $a$ :

$$
\begin{aligned}
c_{d a}^{*} & \leq p_{a} \\
c_{x a}^{*} & \leq \frac{p_{b}}{\tau}
\end{aligned}
$$

We have the following FE for country $a$ :

$$
\bar{\pi}_{a d}\left(n_{a}^{e}+1, n_{b}^{e}\right)+\bar{\pi}_{a x}\left(n_{a}^{e}+1, n_{b}^{e}\right) \leq f_{e} \leq \bar{\pi}_{a d}\left(n_{a}^{e}, n_{b}^{e}\right)+\bar{\pi}_{a x}\left(n_{a}^{e}, n_{b}^{e}\right)
$$

\footnotetext{
${ }^{18}$ In the no free entry analysis, there is no entry and hence no entry costs, so $Y=L+\Pi$ holds.
} 
With the profit functions $\bar{\pi}_{a d}\left(n_{a}^{e}, n_{b}^{e}\right)$ and $\bar{\pi}_{a x}\left(n_{a}^{e}, n_{b}^{e}\right)$ defined as follows:

$$
\begin{aligned}
& \bar{\pi}_{a d}\left(n_{a}^{e}, n_{b}^{e}\right)=\sum_{c \in C_{a}} \sum_{p_{a} \in M\left(c, n_{a}^{e}, n_{b}^{e}\right)} \pi\left(p_{a}, c\right) I\left[c \leq p_{a}\right] j\left(p_{a} \mid c, n_{a}^{e}, n_{b}^{e}\right) f(c) \\
& \bar{\pi}_{a x}\left(n_{a}^{e}, n_{b}^{e}\right)=\sum_{c \in C_{a}} \sum_{p_{b} \in M\left(c, n_{a}^{e}, n_{b}^{e}\right)} \pi\left(p_{b}, \tau c\right) I\left[\tau c \leq p_{b}\right] j\left(p_{b} \mid \tau c, n_{a}^{e}, n_{b}^{e}\right) f(c)
\end{aligned}
$$

The different sets and functions are defined similarly as in the model with one country, but in the two country model we have to condition on the number of entrants in both countries. Equilibrium in the two country model can be defined as follows:

Definition 2. A two country free entry equilibrium consists in country $a=H, F$ for given initial cost distributions $F_{a}(c)$ and $F_{b}(c)$ of numbers of entrants $n_{a}^{e}$ and a varying number of actually producing firms $n_{a}$ and market price $p_{a}$ as a function of the cost draws $\left\{c_{1}^{a}, \ldots, c_{n^{e}}^{a}, c_{1}^{b}, \ldots, c_{n^{e}}^{b}\right\}$. $n_{a}^{e}$ is determined by the FE conditions, equation (43), and the corresponding expression for profit in equation (17). $n_{a}$ is determined by the ranking of the cost draws as described in the proof of proposition 1 and satisfaction of equation (15). $p_{a}$ is for given $n_{a}$ determined by equation (20).

The main difference with the closed economy model is that there might be multiple equilibria for the number of entrants in the open economy. The reason is that there can be different combinations of the number of entrants in both countries that lead to satisfaction of the free entry conditions in the two countries.

Next, we analyse the effect of bilateral trade liberalization:

Proposition 7. Lower trade costs have an ambiguous effect on the market price under free entry. Specifically, (i) as trade costs decline from a prohibitive level to a negligible level, the market price decreases; (ii) when the number of entrants does not change, lower trade costs lead to lower market prices; (iii) when a change in the number of entrants is induced, the market price might either go up or down.

Proof. (i) follows from Proposition 6. (ii) follows from observation 2. (iii) In Appendix C.

Intuitively, the proof in Appendix $\mathrm{C}$ uses the fact that exporting profits increase with lower trade costs for each level of trade costs and each market price ${ }^{19}$ and that domestic profits decline with lower trade costs, as the price distribution shifts to the left for each price. The decrease in domestic profit can dominate the increase in exporting profit and this can induce a lower number of entrants. As a result the price increases and this price increase can dominate the price reduction as a result of lower trade costs, because the exit of domestic firms constitutes a discrete jump. In models with a continuum of firms like Melitz (2003) this is not possible.

The following picture emerges from Proposition 7. As two countries move from autarky to free trade the market price goes down. Along the path of lower trade costs, market prices go down smoothly when no change in the number of entrants is induced. But at certain spikes where violation of the free entry condition causes either more or less entrants, the market price moves with a shock. When more entry is induced the price moves down and when the number of entrants declines the market price jumps up. The latter is possible with lower trade costs when the higher profits from exporting are dominated by lower profits from domestic sales caused by a lower market price.

Empirical work by Besedes and Prusa (2006) and Nitsch (2007) shows that there is considerable variability in the probability of positive trade flows in detailed product categories. The current model provides an explanation for this phenomenon from the simple fact that different cost draws cause significant variability in the price and thus in the possible profitability of exporting. The varying cost draws have a non-negligible and possibly large effect on the market

\footnotetext{
${ }^{19}$ See proof in Appendix $\mathrm{C}$
} 
equilibrium and so might induce moves from zero to one in the trade matrix and vice versa. Other firm heterogeneity models can also explain the moves in and out of exporting, but only as a result of shocks to exogenous variables. Blum, et al. (2013) explain firms moving in and out of exporting by demand shocks combined with a decreasing returns to scale technology. ${ }^{20}$

Our model works with firms living only for one period, limiting its usefullness in explaining the dynamic phenomenon of firms switching between zero and positive trade. But we can expect the prediction on switching export status to carry through in our model if firms would live for multiple periods and subject to an exogenous death probability. As cost draws of newly entering firms replacing died firms would have a nonmarginal impact on the market price, this could still explain switching export status of firms in the market. In the current model we can only claim like Blum, et al. (2013) that identical firms (with the same productivity) might be able to export in one period, whereas they are not able to export in a next period. In Blum, et al. (2013) the changed exporter status of identical firms is explained with exogenous demand shocks, whereas in our model the changed exporter status emerges endogenously from varying market conditions as a result of varying cost draws.

\subsection{Trade with Free Entry: Welfare}

Like the case without free entry we work with equal sectors. Using equation (40) for income $Y$ and $P_{U}=p$ welfare per worker is given by:

$$
\begin{aligned}
W & =\frac{Y}{L P_{U}} \\
& =\frac{L+n^{e}\left(\bar{\pi}-f_{e}\right)}{L p}
\end{aligned}
$$

Comparing equation (44) with the expression for welfare without free entry, equation (33), makes clear that without free entry the term $n^{e} f_{e}$ can be omitted. There is no entry and hence no entry costs. Aggregate profit income $\Pi$ is equal to average profit unconditional upon entry, $\bar{\pi}$, times the number of entrants, $n^{e}$. We can make the following statement on the effect of trade liberalization under free entry:

Proposition 8. The welfare effect of bilateral trade liberalization with free entry (i) is identical to the effect without free entry in Propositions 4-5 if the number of entrants does not change and (ii) can be both positive and negative when the number of entrants changes.

Proof. (i) When the number of entrants does not change, the FE condition has no effect and welfare changes are identical to the no free entry case. (ii) (iii) In Appendix C

(i) follows from the fact that welfare under free entry is identical to welfare without free entry, except for the term $n^{e} f_{e}$. If the number of entrants does not change $n^{e} f_{e}$ is not affected and so the welfare effects are identical with and without free entry. (ii) is proved by example. Two examples are considered. In the first example a reduction in trade costs can lead to a reduction in the number of entrants, because of lower domestic profit dominating increased exporting profit. ${ }^{21}$ As a result, the expected market price rises leading to a reduction in welfare. ${ }^{22}$ In the second example the number of entrants increases in response to lower trade costs. The increase

\footnotetext{
${ }^{20}$ Working with decreasing returns to scale Blum, et al. (2013) generate a negative effect of domestic demand shocks on exporter status of firms, which they confirm empirically with Chilean data. This mechanism is absent in our constant returns to scale model.

${ }^{21}$ It seems paradoxical that the decrease in domestic profit due to a lower price causes exit and thereby raises the price in the end. This result is driven by the fact that the old equilibrium with two entrants in both countries is not an equilibrium anymore, as expected profit would be lower than sunk entry costs.

${ }^{22}$ Due to the reduction in the number of entrants and thus reduced competitive pressure expected profit income will rise, but in the example considered the effect of the price increase on welfare dominates, thus reducing welfare.
} 
in exporting profit dominates the reduction in domestic profit. The additional entry leads to a reduction in the expected price and therefore an increase in welfare. ${ }^{23}$

\subsection{Zeros and Fob Prices}

Recent literature emphasizes the issue of zero flows in the bilateral trade matrix (Baldwin and Harrigan, 2010; Helpman, Melitz and Rubinstein, 2008). In this section we explore the effect of distance and importing country size on the probability of zero trade and on fob prices. We start by noticing that the probability of zero trade flows and fob export prices always move in the same direction. The probability of zero export flows in a certain sector from country $a$ to $b$ is determined by the exporting cutoff cost level, $c_{a x}^{*}=\frac{p_{b}}{\tau_{a b}}$. When the exporting cutoff cost level is smaller than the lower bound of the cost distribution $\underline{c}$, there are zero exports with certainty. So, the probability of zero export flows increases, when the exporting cutoff cost level declines. The cutoff level is equal to the fob export price, as all firms charge the same price under oligopoly. Hence, when the cutoff cost level moves down, the probability of a zero trade flow increases and the fob price goes down. To be brief we therefore only report the effect on the probability of non-zero trade flows.

We start with the effect of distance, mimicked by a decrease in iceberg trade costs:

Proposition 9. A shorter distance between trading partners as mimicked by lower iceberg trade costs leads to (i) a smaller probability of zero trade flows when the number of entrants in both countries does not change; (ii) a smaller probability of zero trade flows, when the number of entrants in the importing country decreases due to lower trade costs; (iii) an indeterminate effect on the probability of zero trade flows, when the number of entrants in the importing country rises because of lower trade costs.

Proof. (i) follows from the fact that without a change in the number of entrants the elasticity is between 0 and $1,0<\varepsilon_{p_{a}, \tau_{b a}}<1$, as shown in equation (22). Therefore $c_{a x}^{*}=\frac{p_{b}}{\tau_{a b}}$ rises with a lower $\tau_{a b}$. (ii) follows from the fact that a decline in the number of entrants raises the market price $p_{b}$. Therefore, $c_{a x}^{*}=\frac{p_{b}}{\tau_{a b}}$ rises with lower trade costs. (iii) follows from the fact that the market price decreases when the number of entrants rises. Therefore, the change in $c_{a x}^{*}=\frac{p_{b}}{\tau_{a b}}$ is indeterminate.

Next we concentrate on the effect of importing and exporting country size on the probability of zero trade flows and export price:

Proposition 10. A larger market size in both the importing and exporting country has an ambiguous effects on the probability of zero trade flows: (i) no effect on the probability of zero trade flows when the number of entrants in the market does not change; (ii) a positive effect on the probability of zero trade flows when entry in the importing country or the exporting country is induced due to a larger market size in the importing or exporting country.

Proof. (i) follows directly from Proposition 3 and (ii) It is shown that the expected market price in country $b, E p_{b}$ and therefore $E c_{a x}^{*}=\frac{E p_{b}}{\tau}$ declines in market size $L_{b}$. Therefore, the probability of zero trade flows from $a$ to $b$ declines in importer market size $L_{b}$. The proof of the effect of exporter market size $L_{a}$ is analogue. There are four steps to the proof. First, it follows from equation (17) that $\pi(p, c)$ is rising in $L$. Hence, for a sufficiently large change in $L_{b}$, the FE in equation (43) will be violated and $n_{a}^{e}$ has to adjust. Second, from equation (41) it follows that $\pi\left(p^{b}, \tau c\right)$ rises in $p^{b}$. Third, FOSD of the probability density function $J\left(\tau p_{b} \mid \tau c, n_{a}^{e}, n_{b}^{e}\right)$ over $J\left(p_{b} \mid \tau c, n_{a}^{e}+1, n_{b}^{e}\right)$ and $\pi\left(p^{b}, \tau c\right)$ rising in $p^{b}$ implies that $n_{a}^{e}$ has to increase to restore the free entry condition in equation (16) after an increase in $L_{b}$. Fourth, a larger $n_{a}^{e}$ as a result of a

\footnotetext{
${ }^{23}$ In this example, expected profit income will fall as a result of additional entry and thus more competitive pressure, but like in the first example the effect of the lower price will dominate, thus raising welfare.
} 
larger $L_{b}$ and FOSD of $J\left(\tau p_{b} \mid \tau c, n_{a}^{e}, n_{b}^{e}\right)$ over $J\left(p_{b} \mid \tau c, n_{a}^{e}+1, n_{b}^{e}\right)$ implies that $E p^{b}$ declines in $L_{b}$. Alternatively, in the first step $n_{b}^{e}$ could adjust to restore FE in both countries, also leading to a decline in $E p^{b}$ by the same sequence of steps.

The first claim is implied by the fact that market size does not affect the market price when the number of entrants does not change, which is pointed out in Proposition 3. The second claim follows from a reasoning analogue to the result in Proposition 6 that a larger market induces more entry and lower prices. With two countries, the additional entry can either take place in one of the two countries, depending upon how close the expected profit was to the sunk entry costs before market extension. However, in both cases the effect is a lower market price and therefore a larger probability of zero trade flows. Also, a larger market size in both the importing and exporting country leads to more entry and thus a lower market price.

Baldwin and Harrigan (2010) compare different models of international trade on their predictions of the effect of distance and importing country size on the probability of zero trade flows and fob prices. From table 1 in their paper it is clear that the model in this paper generates results more consistent with the Melitz and Ottaviano (2008) model than the one proposed by Baldwin and Harrigan (2010). However, it is important to note differences in starting points. The model of Baldwin and Harrigan (2010) emphasizes product differentiation and quality differences to explain pricing, while we have sterilized such issues here. The probability of zero trade flows rises with distance both in our model (in the no-free-entry case) and in Baldwin and Harrigan (2010). A larger distance makes it more likely in both markets that trade costs are too high and that no firm is productive enough to sell profitably in the export market. However, the probability of zero trade flows rises in importing country size in our model and declines in importing country size in Baldwin and Harrigan (2010). The intuition in our model is that a larger market leads to tougher competition, more entry of firms and lower prices. Henceforth, it becomes harder to export to that market. The model of Baldwin and Harrigan (2010) features fixed export costs. In a larger market it is therefore easier to earn these fixed costs back and therefore also the less productive firms with lower quality and lower price can sell in the market profitably. A larger market also implies a lower price index and therefore less sales for an individual firm, making it more difficult to sell profitably in the export market. On net, the direct effect of market size dominates. ${ }^{24}$

In terms of prices, a larger distance leads to higher fob export prices in Baldwin and Harrigan (2010) and lower export prices in our model (in the no-free-entry case). In both models a larger distance makes it harder to export and therefore only more productive firms can export. In our model more productive firms charge lower prices, whereas in the Baldwin and Harrigan (2010) quality model they charge higher prices because they can switch to higher quality. Finally, the export price declines in both models in the importing country size. The reason is different, however. In our model prices are lower in a larger market due to intenser competition and for given trade costs this leads to lower export prices as well. In Baldwin and Harrigan (2010) it is easier to earn back the fixed export costs in a larger market. Therefore, also lower quality, lower price exporters can sell profitably and the average export price will be lower.

\section{$5 \quad$ Summary and Conclusions}

We have developed a model of firm heterogeneity and trade in an oligopoly setting featuring large non-atomistic firms. This approach deviates from current firm heterogeneity models, as the number of firms is discrete and the equilibrium exhibits churn. Some of the results are familiar from the recent Bertrand and Chamberlinian monopolistic competition literature with cost heterogeneity. Market prices generally decline, the least productive firms get squeezed

\footnotetext{
${ }^{24}$ While we stress markups here, there is no effect of market size on profit margins in the model of Baldwin and Harrigan (2010), because they work with fixed markups.
} 
out of the market and exporting firms gain market share when trade costs fall. With free entry welfare might also decrease with lower trade costs, this in deviation from the current firm heterogeneity literature. Lower trade costs can cause exit of domestic firms and this constitutes a discrete drop in the number of firms leading to higher prices. Without free entry, we extend the result by Brander and Krugman (1983) on the increased costs of cross-hauling and show that welfare has to increase with trade liberalization when the firm size distribution follows a power law. We also generated predictions on zero trade flows and export prices as a function of distance and importing market size and showed that the probability of zero trade flows varies endogenously over time due to entry and exit of firms. Possible extensions of the model are the introduction of wage differences between the two countries, political economy applications (as domestic industry concentration is endogenous to the evolution of trade policy), and specifying a distribution of costs enabling simulations with the model with more countries and more sectors. 


\section{References}

Atkeson, A. And A. Burstein (2008), "Pricing-to-Market, Trade Costs, and International Relative Prices," American Economic Review 98(5): 1998-2031.

Axtell, Robert L. (2001), "Zipf Distribution of U.S. Firm Sizes," Science 293 (5536): 18181820 .

Baldwin, R. And J. Harrigan (2010), "Zeros, Quality and Space: Trade Theory and Trade Evidence," American Economic Journal: Microeconomics 3(2): 60-88.

Bandyopadhyay, S. (1997), "Demand Elasticities, Asymmetry and Strategic Trade Policy," Journal of International Economics 42: 167-177.

Besedes, T. And T. J. Prusa (2006), 'Product Differentiation and Duration of US Import Trade,' Journal of International Economics 70: 339-358.

Bernard, A.B., J. Eaton, J.B. Jensen, and S. Kortum (2003), "Plants and Productivity in International Trade," American Economic Review 93(4): 1268-1290.

Bernard, A.B. And J. B.Jensen (2004), "Exporting and Productivity in the USA," Oxford Review of Economic Policy 20(3).

Blum, Bernardo S., Sebastian Claro and Ignatius J. Horstmann (2013). "Occasional and Perennial Exporters." Journal of International Economics Forthcoming.

Bombardini, M. (2008), "Firm Heterogeneity and Lobby Participation," Journal of International Economics 75: 329-348.

Brander, J. and P. Krugman (1983), "A 'Reciprocal Dumping' Model of International Trade," Journal of International Economics 15: 313-321.

Di Giovanni, Julian And Andrei A. Levchenko (2013). "Firm Entry, Trade, and Welfare in Zipf's World." Journal of International Economics Forthcoming

Di Giovanni, Julian and Andrei A. Levchenko (2013). "Country Size, International Trade, and Aggregate Fluctuations in Granular Economies." Journal of Political Economy Forthcoming.

Feenstra, R. (2010), "Measuring the Gains from Trade Under Monopolistic Competition," Canadian Journal of Economics 43(1): 1-28.

Francois, J. And H. Horn (2008), "Antitrust in Open Economies," in V. Ghosal and J. Stennek, eds., The Political Economy of Antitrust, North-Holland Press, 2008.

Francois, J. And D. Roland-Holst (1997), "Scale Economies and Imperfect Competition," in J.F. Francois and K.A. Reinert, eds., Applied Methods for Trade Policy Analysis: A Handbook, Cambridge University Press , 1997.

Francois, J., M. Manchin and W. Martin (forthcoming), "Market Structure in General Equilibrium Models of Open Economies," in P.B. Dixon and D.W. Jorgenson, eds., Handbook of Computable General Equilibrium modelling, Elsevier:North-Holland.

Friberg, Richard and Mattias Ganslandt (2006), "An Empirical Assessment of the Welfare Effects of Reciprocal Dumping," Journal of International Economics 70: 1-24.

Fabio Ghironi and Marc J. Melitz (2005). "International Trade and Macroeconomic Dynamics with Heterogeneous Firms." Quarterly Journal of Economics 120(3): 865-915. 
Helpman, E., M.J. Melitz, And Y. Rubinstein (2008), "Estimating Trade Flows: Trading Partners and Trading Volumes," Quarterly Journal of Economics 123: 441-487.

Hoekman, B. And H.L. Kee (2007), "Imports, entry and competition law as market disciplines," European Economic Review 51(4): 831-858.

Hoekman, B, H.L. Kee and M. Olarreaga (2004), "Tariffs, Entry Regulation and Markups: Country Size Matters," Contributions to Macroeconomics 4(1): Article 8.

Hopenhayn, H. A. (1992), "Entry, Exit, and Firm Dynamics in Long Run Equilibrium," Econometrica 60(5): 1127-1150.

Leahy, D. And P. Neary (2011), "Oligopoly and Trade," in D. Bernhofen, R. Falvay, D. Greenaway and U. Kreickemeier (eds.), Palgrave Handbook of International Trade, Palgrave Macmillan.

Melitz, M.J. (2003), "The Impact of Trade on Intra-Industry Reallocations and Aggregate Industry Productivity," Econometrica 71(6): 1695-1725.

Melitz, M.J. and G.I.P. Ottaviano (2008), "Market Size, Trade, and Productivity," Review of Economic Studies 75(1): 295-316.

Neary, J.P. (2009), "International Trade in General Oligopolistic Equilibrium," Mimeo University of Oxford.

NeARY, J.P. (2010), "Two and A Half Theories of Trade," The World Economy 33(1): 1-19.

Nitsch, V. (2007), 'Die Another Day: Duration in German Import Trade,' CESifo Working Paper No. 2085.

Tybout, J.R. (2001), "Plant and Firm-Level Evidence on New Trade Theories," in: Harrigan J. (ed.), Handbook of International Economics 38, Basil-Blackwell. Also: NBER Working Paper No. 8414.

U.S: Census Bureau (2006), Concentration Ratios: 2002 Economic Census, U.S. Department of Commerce:

Van Long, N. And A. Soubeyran (1997), "Cost Heterogeneity, Industry Concentration and Strategic Trade Policies," Journal of International Economics 43: 207-220.

Van Long, N., H. Raff And F. Staehler (2011), "Innovation and Trade with Heterogeneous Firms," Journal of International Economics 84: 149-159. 


\section{Appendix A Basic Model}

The appendices show how to derive equations from the main text.

Equation (7): SOC

Differentiating the FOC in equation 6 with respect to firm sales $q_{i}$ leads to:

$$
\frac{\partial^{2} \pi_{i}}{\partial q_{i}^{2}}=-\frac{2 p}{\sigma q}+\frac{(\sigma+1) p}{\sigma^{2} q} \theta_{i}
$$

Substituting the first order condition, $\theta_{i}=\sigma \frac{p-c_{i}}{p}$ into (A.1), generates equation (7) in the main text:

$$
\begin{aligned}
\frac{\partial^{2} \pi_{i}}{\partial q_{i}^{2}} & =-\frac{1}{\sigma} \frac{p}{q}\left[2-\frac{\sigma+1}{\sigma} \theta_{i}\right]=-\frac{1}{\sigma} \frac{p}{q}\left[2-\frac{\sigma+1}{\sigma} \sigma \frac{p-c_{i}}{p}\right] \\
& =-\frac{1}{\sigma} \frac{p}{q} \frac{2 p-(\sigma+1) p+(\sigma+1) c_{i}}{p}=-\frac{1}{\sigma} \frac{p}{q} \frac{(\sigma+1) c_{i}-(\sigma-1) p}{p}
\end{aligned}
$$

From the first expression it is clear that the SOC is satisfied whenever $\sigma \geq 1$ and $\theta_{i}<1$.

Equation (18)

Differentiating $\pi(p, c)$ from equation (17) with respect to $p$ gives:

$$
\begin{aligned}
d \pi & =\sigma L P_{u}^{\sigma-1}\left(\frac{2(p-c)}{p^{\sigma+1}}-(\sigma+1) \frac{(p-c)^{2}}{p^{\sigma+2}}\right) I[c \leq p] d p+\pi(p, c) d I[c \leq p] \\
& =\frac{\sigma L P_{u}^{\sigma-1}}{p^{\sigma}} \frac{p-c}{p}\left(2-(\sigma+1) \frac{p-c}{p}\right) I[c \leq p] d p+\pi(p, c) d I[c \leq p] \\
& =\frac{L P_{u}^{\sigma-1}}{p^{\sigma}} \theta(c)\left(\frac{(\sigma+1) c-(\sigma-1) p}{p}\right) I[c \leq p] d p+\pi(p, c) d I[c \leq p]
\end{aligned}
$$

\section{Appendix B The No-Free-Entry Case}

Effect of Trade Liberalization on Market Shares in Melitz (2003)

Using the notation in Melitz (2003), the market share of a firm with productivity $\varphi$ on the exporting market, $\theta_{x}(\varphi)$, can be expressed as:

$$
\theta_{x}(\varphi)=\frac{r_{x}(\varphi)}{L}=p(\varphi)^{1-\sigma} P^{\sigma-1}=\left(\frac{\sigma}{\sigma-1} \frac{\tau}{\varphi}\right)^{1-\sigma} P^{\sigma-1}
$$

Log differentiating equation (B.1) wrt $\tau$ gives:

$$
\widehat{\theta_{x}(\varphi)}=(1-\sigma) \widehat{\tau}+(\sigma-1) \widehat{P}
$$

Hence, the relative change is for all firms identical and in absolute terms big firms thus gain more market share.

Equation 21: Direct and indirect effect of trade liberalization in short-run free exit case

The market price is defined in equation (20)

$$
p_{a}=\frac{\sigma}{\sigma\left(n_{d a}+n_{x b}\right)-1}\left(\sum_{i=1}^{n_{d a}} c_{i d a}+\sum_{i=1}^{n_{x b}} \tau c_{i x b}\right)
$$


Totally differentiating equation (B.2) with respect to $p$ and $\tau$, one finds:

$$
\begin{aligned}
d p_{a}= & \sum_{i=1}^{n_{x b}} c_{i x b} d \tau+\frac{\sigma\left(\sum_{i=1}^{n_{d a}} c_{i d a}+\sum_{i=1}^{n_{x b}} \tau c_{i x b}+\sum_{j=1}^{d n_{d a}} c_{j d a}+\sum_{j=1}^{d n_{x b}} \tau c_{j x b}\right)}{\sigma\left(n_{a}+d n_{d a}+d n_{x b}\right)-1} \\
& -\frac{\sigma\left(\sum_{i=1}^{n_{d a}} c_{i d a}+\sum_{i=1}^{n_{x b}} \tau c_{i x b}\right)}{\sigma n_{a}-1}
\end{aligned}
$$

$d n_{x b}$ is the change in the number of exporting firms, i.e the exporting firms that are entering the market because of the change in tariffs and $d n_{d s}$ is the change in the number of domestic firms, i.e. the domestic firms that have to leave the market. These firms that are entering the export market and leaving the domestic market all have marginal costs (inclusive of trade costs for the exporters) equal to the market price. Therefore, equation (B.3) can be written as:

$$
\begin{aligned}
d p_{a}= & \sum_{i=1}^{n_{x b}} c_{i x b} d \tau+\frac{\sigma\left(\sum_{i=1}^{n_{d a}} c_{i d a}+\sum_{i=1}^{n_{x b}} \tau c_{i x b}+\left(d n_{x b}+d n_{d a}\right) p\right)}{\sigma\left(n_{a}+d n_{x b}+d n_{d a}\right)-1}-\frac{\sigma\left(\sum_{i=1}^{n_{d a}} c_{i d a}+\sum_{i=1}^{n_{x b}} \tau c_{i x b}\right)}{\sigma n_{a}-1} \\
= & \sum_{i=1}^{n_{x b}} c_{i x b} d \tau+\frac{\sigma\left(\sum_{i=1}^{n_{d a}} c_{i d a}+\sum_{i=1}^{n_{x b}} \tau c_{i x b}+\left(d n_{x b}+d n_{d a}\right) p\right)\left(\sigma n_{s}-1\right)}{\left(\sigma\left(n_{a}+d n_{x b}+d n_{d a}\right)-1\right)\left(\sigma n_{a}-1\right)} \\
= & \frac{\sigma\left(\sum_{i=1}^{n_{d a}} c_{i d a}+\sum_{i=1}^{n_{x b}} \tau c_{i x b}\right)\left(\sigma\left(n_{a}+d n_{x b}+d n_{d a}\right)-1\right)}{\left(\sigma\left(n_{a}+d n_{x b}+d n_{d a}\right)-1\right)\left(\sigma n_{a}-1\right)} \\
= & \sum_{i=1}^{n_{x b}} c_{i x b} d \tau \\
= & \sum_{i=1}^{n_{x b}} c_{i x b} d \tau \quad \frac{\sigma\left(d n_{x b}+d n_{d a}\right) p_{a}\left(\sigma n_{a}-1\right)-\sigma\left(\sum_{i=1}^{n_{d a}} c_{i d a}+\sum_{i=1}^{n_{x b}} \tau c_{i x b}\right) \sigma\left(d n_{x b}+d n_{d a}\right)}{\left(n_{a}-1+d n_{x b}+d n_{d a}\right)\left(n_{a}-1\right)}
\end{aligned}
$$

So, the effect through a change in the number of firms is zero. The direct effect remains which is positive. Using relative changes, one arrives at equation (21) in the main text.

Equation 19

There is a continuum of equal sectors with mass 1 . With a continuum of equal sectors with mass $1, \Pi$ is equal to:

$$
\begin{aligned}
\Pi & =p q-\sum_{i=1}^{n} c_{i} q_{i} \\
& =p q-q \sum_{i=1}^{n} c_{i} \theta_{i} \\
& =\frac{p-\sum_{i=1}^{n} c_{i} \theta_{i}}{p^{\sigma}} P_{U}^{\sigma-1}(L+\Pi) \\
& =\frac{p-\tilde{c}}{p}(L+\Pi)
\end{aligned}
$$


Solving for $\Pi$ and $L+\Pi$ from equation (B.4) gives:

$$
\begin{aligned}
\Pi & =\frac{p-\tilde{c}}{\tilde{c}} L \\
L+\Pi & =\frac{p}{\tilde{c}} L
\end{aligned}
$$

\section{Observation 6}

As proof of ambiguity, we offer two examples to show that the welfare effect can go both ways. First, we offer an example of a negative welfare effect from trade liberalization. Suppose there are two identical countries with each three firms and the substitution elasticity $\sigma$ is equal to 1 . They have marginal costs of 1,1 and 2 . The autarky market price will be 2 . The iceberg trade costs are equal to 2. This implies that 2 firms can export, but with a market share of 0 . Equation (36) can be applied to show that a marginal reduction of the tariff decreases welfare by $\frac{1}{2}$.

An example where the welfare effect is positive is the following. Again there are two identical countries with each three firms and $\sigma=1$. Marginal costs are now 1, 3 and 3. The autarky market price is $3 \frac{1}{2}$. Iceberg trade costs are $3 \frac{1}{2}$. So, only one firm can export. When the tariff is reduced from the prohibitive level, the welfare effect from equation (36) is positive and equal to $\frac{8}{15}$.

\section{Proposition 4}

Part (i) From equation (34) the welfare change is a function of the change in $\tilde{c}$. Substituting equations $(27),(28),(29),(31)$ into equation $(35), d \tilde{c}$ can be written as:

$$
d \tilde{c}=\sum_{i=1}^{n_{d}} c_{i} \frac{p-c_{i}}{p} \frac{c_{i}}{p-c_{i}} \varepsilon_{p, \tau} \hat{\tau}+\sum_{i=1}^{n_{x}} \tau c_{i} \frac{p-\tau c_{i}}{p} \frac{\tau c_{i}}{p-\tau c_{i}}\left(\varepsilon_{p, \tau}-1\right) \hat{\tau}+\sum_{i=1}^{n_{x}} \tau c_{i} \frac{p-\tau c_{i}}{p} \hat{\tau}
$$

Using equation (22) one can substitute for the price elasticity in equation (B.7) to get:

$$
\begin{aligned}
d \tilde{c}= & \sum_{i=1}^{n_{d}} \sigma \frac{c_{i}^{2}}{p} \frac{\sum_{i=1}^{n_{x}} \tau c_{i}}{\sum_{i=1}^{n_{d}} c_{i}+\sum_{i=1}^{n_{x}} \tau c_{i}} \hat{\tau}+\sum_{i=1}^{n_{x}} \sigma \frac{\tau^{2} c_{i}^{2}}{p} \frac{\sum_{i=1}^{n_{x}} \tau c_{i}}{\sum_{i=1}^{n_{d}} c_{i}+\sum_{i=1}^{n_{x}} \tau c_{i}} \hat{\tau}-2 \sum_{i=1}^{n_{x}} \sigma \frac{\tau^{2} c_{i}^{2}}{p} \hat{\tau}+\sum_{i=1}^{n_{x}} \sigma \frac{p \tau c_{i}}{p} \hat{\tau} d \tilde{c} \\
= & \sigma \sum_{i=1}^{n_{d}} \frac{c_{i}^{2}}{p} \frac{\sum_{i=1}^{n_{x}} \tau c_{i}}{\sum_{i=1}^{n_{d}} c_{i}+\sum_{i=1}^{n_{x}} \tau c_{i}} \hat{\tau}+\sigma \sum_{i=1}^{n_{x}} \frac{\tau^{2} c_{i}^{2}}{p} \frac{\sum_{i=1}^{n_{x}} \tau c_{i}}{\sum_{i=1}^{n_{d}} c_{i}+\sum_{i=1}^{n_{x}} \tau c_{i}} \hat{\tau} \\
d \tilde{c}= & \left.\frac{-\sigma\left(2 \sum_{i=1}^{n_{x}} \frac{\tau^{2} c_{i}^{2}}{p}-\sum_{i=1}^{n_{x}} \frac{p \tau c_{i}}{p}\right) \frac{\sum_{i=1}^{n_{d}} c_{i}+\sum_{i=1}^{n_{x}} \tau c_{i}}{\sum_{i=1}^{n_{d}} c_{i}+\sum_{i=1}^{n_{x}} \tau c_{i}} \hat{\tau}}{p\left(\sum_{i=1}^{n_{d}} c_{i}+\sum_{i=1}^{n_{x}} \tau c_{i}\right)} * \sum_{i=1}^{n_{i}} c_{i=1}^{n_{x}} \tau c_{i} \hat{\tau}+\sigma \sum_{i=1}^{n_{x}} \tau^{2} c_{i}^{2} \sum_{i=1}^{n_{x}} \tau c_{i} \hat{\tau}-\sigma\left(2 \sum_{i=1}^{n_{x}} \tau^{2} c_{i}^{2}-p \sum_{i=1}^{n_{x}} \tau c_{i}\right)\left(\sum_{i=1}^{n_{d}} c_{i}+\sum_{i=1}^{n_{x}} \tau c_{i}\right) \hat{\tau}\right]
\end{aligned}
$$

Using the expression for price in equation (11) and the definition of $\bar{c}_{O}$ in equation (37), equation (B.8) can be rewritten as:

$$
d \tilde{c}=\frac{\sigma^{2}}{p^{2}(\sigma n-1)}\left[\left(\sum_{i=1}^{n_{d}} c_{i}^{2}+\sum_{i=1}^{n_{x}} \tau^{2} c_{i}^{2}\right) \sum_{i=1}^{n_{x}} \tau c_{i} \hat{\tau}-\left(2 \sum_{i=1}^{n_{x}} \tau^{2} c_{i}^{2}-p \sum_{i=1}^{n_{x}} \tau c_{i}\right) n \bar{c}_{O} \hat{\tau}\right]
$$


Substituting the expression for the unweighted variance in equation (38) into equation (B.9) leads to:

$$
d \tilde{c}=\frac{\sigma^{2}}{p^{2}(\sigma n-1)}\left[\left((n-1) s_{c}^{2}+n \mu_{c}^{2}\right) \sum_{i=1}^{n_{x}} \tau c_{i} \hat{\tau}-\left(2 \sum_{i=1}^{n_{x}} \tau^{2} c_{i}^{2}-p \sum_{i=1}^{n_{x}} \tau c_{i}\right) n \bar{c}_{O} \hat{\tau}\right]
$$

Bringing the summation of $\sum_{i=1}^{n_{x}} \tau c_{i}$ outside the brackets in equation (B.10) gives:

$$
d \tilde{c}=\frac{\sigma^{2}}{p^{2}(\sigma n-1)} \sum_{i=1}^{n_{x}} \tau c_{i}\left[n \bar{c}_{O}\left(\bar{c}_{O}+p-2 \tau c_{i}\right)+(n-1) s_{c}^{2}\right] \hat{\tau}
$$

Part (i) of Proposition 4 follows from the fact that the first term between square brackets $\bar{c}_{O}\left(\bar{c}_{O}+p-2 \tau c_{i}\right)$ is positive if the average of average costs $\mu_{c}$ and $p$ is larger than marginal costs inclusive of trade costs, $\tau c_{i}$ for all firms $i$.

For part (ii), we substitute equations (9), (29), (31) and ((22) into equation (35) and write $d \tilde{c}$ as:

$$
\begin{aligned}
d \tilde{c} & =\sum_{i=1}^{n_{d}} c_{i} \theta_{i d} \hat{\theta}_{i d}+\sum_{i=1}^{n_{x}} \tau c_{i} \theta_{i x} \hat{\theta}_{i x}+\sum_{i=1}^{n_{x}} \tau c_{i} \theta_{i x} \hat{\tau} \\
d \tilde{c} & =\sum_{i=1}^{n_{d}} \sigma \frac{c_{i}^{2}}{p} \hat{p}+\sum_{i=1}^{n_{x}} \sigma \frac{\tau^{2} c_{i}^{2}}{p}(\hat{p}-\hat{\tau})+\sum_{i=1}^{n_{x}} \sigma \tau c_{i} \frac{p-\tau c_{i}}{p} \hat{\tau} \\
d \tilde{c} & =\frac{1}{p} \sum_{i=1}^{n_{d}} \sigma c_{i}^{2} \frac{\sum_{i=1}^{n_{x}} \tau c_{i}}{\sum_{i=1}^{n_{d}} c_{i}+\sum_{i=1}^{n_{x}} \tau c_{i}} \hat{\tau}-\sum_{i=1}^{n_{x}} \sigma \tau^{2} c_{i}^{2} \frac{\sum_{i=1}^{n_{d}} c_{i}}{\sum_{i=1}^{n_{d}} c_{i}+\sum_{i=1}^{n_{x}} \tau c_{i}} \hat{\tau}+\sum_{i=1}^{n_{x}} \sigma \tau c_{i}\left(p-\tau c_{i}\right) \frac{\sum_{i=1}^{n_{d}} c_{i}+\sum_{i=1}^{n_{x}} \tau c_{i}}{\sum_{i=1}^{n_{d}} c_{i}+\sum_{i=1}^{n_{x}} \tau c_{i}} \\
d \tilde{\tau} & =\frac{1}{p} \frac{\sigma}{\sum_{i=1}^{n_{d}} c_{i}+\sum_{i=1}^{n_{x}} \tau c_{i}}\left(\sum_{i=1}^{n_{d}} c_{i}^{2} \sum_{i=1}^{n_{x}} \tau c_{i} \hat{\tau}-\sum_{i=1}^{n_{x}} \tau^{2} c_{i}^{2} \sum_{i=1}^{n_{d}} c_{i} \hat{\tau}+\sum_{i=1}^{n_{x}} \tau c_{i}\left(p-\tau c_{i}\right)\left(\sum_{i=1}^{n_{d}} c_{i}+\sum_{i=1}^{n_{x}} \tau c_{i}\right) \hat{\tau}\right) \\
d \tilde{c}= & \frac{\sigma^{2}}{p^{2}(\sigma n-1)}\left(\sum_{i=1}^{n_{d}} c_{i}^{2} \sum_{i=1}^{n_{x}} \tau c_{i} \hat{\tau}-\sum_{i=1}^{n_{x}} \tau^{2} c_{i}^{2} \sum_{i=1}^{n_{d}} c_{i} \hat{\tau}+\left(p \sum_{i=1}^{n_{x}} \tau c_{i}-\sum_{i=1}^{n_{x}} \tau^{2} c_{i}^{2}\right)\left(\sum_{i=1}^{n_{d}} c_{i}+\sum_{i=1}^{n_{x}} \tau c_{i}\right) \hat{\tau}\right)
\end{aligned}
$$

The third term between brackets in equation (B.12) should be positive as $p \geq \tau c_{i} \forall i$. Hence, we can impose the following condition:

$$
p \sum_{i=1}^{n_{x}} \tau c_{i}\left(\sum_{i=1}^{n_{d}} c_{i}+\sum_{i=1}^{n_{x}} \tau c_{i}\right)-\sum_{i=1}^{n_{x}} \tau^{2} c_{i}^{2} \sum_{i=1}^{n_{x}} \tau c_{i} \geq \sum_{i=1}^{n_{x}} \tau^{2} c_{i}^{2}
$$

Substituting the condition in (B.13) into the first two terms of $d \tilde{c}$ in equation (B.12) implies the following inequality:

$$
\begin{aligned}
d \tilde{c} & \geq\left[\sum_{i=1}^{n_{d}} c_{i}^{2} \sum_{i=1}^{n_{x}} \tau c_{i}-p \sum_{i=1}^{n_{x}} \tau c_{i}\left(\sum_{i=1}^{n_{d}} c_{i}+\sum_{i=1}^{n_{x}} \tau c_{i}\right)+\sum_{i=1}^{n_{x}} \tau^{2} c_{i}^{2} \sum_{i=1}^{n_{x}} \tau c_{i}\right] \hat{\tau} \\
d \tilde{c} & \geq \sum_{i=1}^{n_{x}} \tau c_{i}\left[\left(\sum_{i=1}^{n_{d}} c_{i}^{2}+\sum_{i=1}^{n_{x}} \tau^{2} c_{i}^{2}\right)-p\left(\sum_{i=1}^{n_{d}} c_{i}+\sum_{i=1}^{n_{x}} \tau c_{i}\right)\right] \hat{\tau} \\
d \tilde{c} & \geq \sum_{i=1}^{n_{x}} \tau c_{i}\left[(n-1) s_{c}^{2}+n \bar{c}_{O}^{2}-p n \bar{c}_{O}\right] \hat{\tau} \\
d \tilde{c} & \geq \sum_{i=1}^{n_{x}} \tau c_{i}\left[(n-1) s_{c}^{2}+n \bar{c}_{O}\left(\bar{c}_{O}-p\right)\right] \hat{\tau} \\
d \tilde{c} & \geq \sum_{i=1}^{n_{x}} \tau c_{i}\left[(n-1) s_{c}^{2}+n \bar{c}_{O}\left(\bar{c}_{O}-\frac{\sigma n}{\sigma n-1} \bar{c}_{O}\right)\right] \hat{\tau} \\
d \tilde{c} & \geq \sum_{i=1}^{n_{x}} \tau c_{i}\left[s_{c}^{2}-\frac{n}{n-1} \frac{1}{\sigma n-1} \bar{c}_{O}^{2}\right] \hat{\tau}
\end{aligned}
$$


So, from the inequality in (B.14) $d \tilde{c}$ is positive if $\frac{s_{c}}{\bar{c}_{O}} \geq \sqrt{\frac{n}{n-1} \frac{1}{(\sigma n-1)}}$.

\section{Appendix C Free Entry Case}

$\bar{\pi}$ rising in $p$ (used in proof Proposition 6)

Using equations (16)-(17), substituting $P_{U}=p$ and equation (40), $\bar{\pi}$ can be written as follows:

$$
\bar{\pi}=\sum_{\widetilde{c} \in C} \sum_{z \in M\left(\widetilde{c}, n^{e}\right)} \sigma\left(L+n^{e}\left(\bar{\pi}-f_{e}\right)\right)\left(\frac{z-\widetilde{c}}{z}\right)^{2} I[\widetilde{c} \leq z] j\left(z \mid \widetilde{c}, n^{e}\right) f(\widetilde{c})
$$

We sum over $z$ and $\widetilde{c}$ instead of over $p$ and $c$, as we are interested in the effect of a change in a specific value of the price, $p$, on expected profit, summed across all possible price levels $z$. Log differentiating equation (C.1) with respect to $\widehat{\bar{\pi}}$ and $p$ gives:

$$
\begin{aligned}
& \widehat{\bar{\pi}}=\frac{n^{e} \bar{\pi}}{L+n^{e}\left(\bar{\pi}-f_{e}\right)} \widehat{\bar{\pi}}+\frac{\sum_{\widetilde{c} \in C} \frac{\partial\left(\frac{p-\widetilde{c}}{p}\right)^{2} I[\widetilde{c} \leq p] j\left(p \mid \widetilde{c}, n^{e}\right)}{\partial p} f(\widetilde{c}) p}{\sum_{\widetilde{c} \in C} \sum_{z \in M\left(\widetilde{c}, n^{e}\right)}\left(\frac{z-\widetilde{c}}{z}\right)^{2} I[\widetilde{c} \leq z] j\left(z \mid \widetilde{c}, n^{e}\right) f(\widetilde{c})} \widehat{p} \\
& \widehat{\bar{\pi}}=\frac{L+n^{e}\left(\bar{\pi}-f_{e}\right)}{L-f_{e}} \frac{\sum_{\widetilde{c} \in C} \frac{2 \widetilde{c}(p-\widetilde{c})}{p} I[\widetilde{c} \leq p] j\left(p \mid \widetilde{c}, n^{e}\right) f(\widetilde{c})+\left(\frac{p-\widetilde{c}}{p}\right)^{2} j\left(p \mid \widetilde{c}, n^{e}\right) \frac{d I[\widetilde{c} \leq p]}{d p} p}{\sum_{\widetilde{c} \in C} \sum_{z \in M\left(\widetilde{c}, n^{e}\right)}\left(\frac{z-\widetilde{c}}{z}\right)^{2} I[\widetilde{c} \leq z] j\left(z \mid \widetilde{c}, n^{e}\right) f(\widetilde{c})} \widehat{p}
\end{aligned}
$$

As $\frac{d I[\widetilde{c} \leq p]}{d p} \geq 0, \bar{\pi}$ rises in $p$.

Proposition 7 (iii) and Proposition 8 (ii)

We consider two examples. In the first example lower trade costs induce a lower number of entrants, a higher expected price and lower welfare. This example thus proves Proposition 7 (iii) and the first part of Proposition 8 (ii). In the second example lower trade costs generate additional entry, a lower expected price and higher welfare. This example proves the second part of Proposition 8 (ii). In both examples there are two identical countries indicated by subscript $a$ and $b$. There are two marginal cost levels in the initial cost distribution in both countries, $c_{1}=1, c_{2}=2$, both with probability $1 / 2$.

In the first example iceberg trade costs are set at the marginally prohibitive level of $\tau=8 / 3$, implying that exporting profits are 0 . Sunk entry costs are such that there are two entrants in both countries, $n_{a}^{e}=n_{b}^{e}=2$. There are sixteen possible cost draws (as there are four firms) resulting in four corresponding combinations of firm 1 cost draws in country 1 and prices, i.e. combinations of $c$ and $p$. The market price $p_{a}$ is determined using equation (20) and profit using equation (17). The implied cases with the cost probabilities $f\left(c_{a 1}\right)$ and price probabilities for given cost and number of firms, $J\left(p_{a} \mid c_{1 a}, n_{a}^{e}, n_{b}^{e}\right)$ and the overall probability $P=J\left(p_{a} \mid c_{1 a}, n_{a}^{e}, n_{b}^{e}\right) f\left(c_{a 1}\right)$ are displayed in table $2:^{25}$

From table 2 the expected price $E p_{a}$ is equal to 2 and expected profits are given by $\bar{\pi}_{a}=\frac{3}{16} Y$. Expected profit minus entry costs can be calculated using the expression for $Y$ in equation (40):

$$
\bar{\pi}_{a}-f_{e}=\frac{6}{5}\left(L-\frac{16}{3} f_{e}\right)
$$

Hence, setting $f_{e}=\frac{3}{16} L$ implies zero expected profit net of entry costs. With this level of $f_{e}$ the FE is just satisfied and there are two entrants in both countries:

$$
\bar{\pi}_{a}(3,2) \leq f_{e}=\bar{\pi}_{a}(2,2)
$$

Suppose trade costs fall to $\tau=2.65=53 / 20$. This implies that the market price falls for case 4 in table 2 . The new situation is displayed in table 3 .

\footnotetext{
${ }^{25} \mathrm{~A}$ table with the underlying cost draws and probabilities implying table 2 is available upon request.
} 
Table 2: Cost draws, resulting market prices and probabilities in example 1 with $n_{a}^{e}=2, n_{b}^{e}=2$, $\tau=8 / 3$

\begin{tabular}{|l|l|l|l|l|l|l|}
\hline$\tau=8 / 3$ & $c_{a 1}$ & $p_{a}$ & $\pi_{a}\left(p_{a}, c_{a 1}\right)$ & $P$ & $J\left(p_{a} \mid c_{1 a}, n_{a}^{e}, n_{b}^{e}\right)$ & $f\left(c_{a 1}\right)$ \\
\hline 1. & 1 & $\frac{4}{3}$ & $2 Y \frac{\left(\frac{4}{3}-1\right)^{2}}{\frac{4}{3}}=\frac{Y}{8}$ & $\frac{1}{4}$ & $\frac{1}{2}$ & $\frac{1}{2}$ \\
2. & 1 & 2 & $2 Y \frac{(2-1)^{2}}{2^{2}}=\frac{Y}{2}$ & $\frac{1}{4}$ & $\frac{1}{2}$ & $\frac{1}{2}$ \\
\hline 3. & 2 & 2 & $2 Y\left(\frac{2-2}{2}\right)=0$ & $\frac{1}{4}$ & $\frac{1}{2}$ & $\frac{1}{2}$ \\
\hline 4. & 2 & $\frac{8}{3}$ & $2 Y\left(\frac{\frac{8}{3}-2}{\frac{8}{3}}\right)^{2}=\frac{Y}{8}$ & $\frac{1}{4}$ & $\frac{1}{2}$ & $\frac{1}{2}$ \\
\hline
\end{tabular}

Table 3: Cost draws, resulting market prices and probabilities in example 1 with $n_{a}^{e}=2, n_{b}^{e}=2$, $\tau=53 / 20$

\begin{tabular}{|l|l|l|l|l|l|l|}
\hline$\tau=5 / 2$ & $c_{a 1}$ & $p_{a}$ & $\pi_{a}\left(p_{a}, c_{a 1}\right)$ & $P$ & $J\left(p_{a} \mid c_{1 a}, n_{a}^{e}, n_{b}^{e}\right)$ & $f\left(c_{a 1}\right)$ \\
\hline 1. & 1 & $\frac{4}{3}$ & $2 Y \frac{\left(\frac{4}{3}-1\right)^{2}}{\frac{4}{3}}=\frac{Y}{8}$ & $\frac{1}{4}$ & $\frac{1}{2}$ & $\frac{1}{2}$ \\
2. & 1 & 2 & $2 Y \frac{(2-1)^{2}}{2^{2}}=\frac{Y}{2}$ & $\frac{1}{4}$ & $\frac{1}{2}$ & $\frac{1}{2}$ \\
\hline 3. & 2 & 2 & $2 Y\left(\frac{2-2}{2}\right)=0$ & $\frac{1}{4}$ & $\frac{1}{2}$ & $\frac{1}{2}$ \\
\hline 4. & 2 & $\frac{93}{35}$ & $2 Y\left(\frac{\frac{18}{7}-2}{\frac{18}{7}}\right)^{2}=\frac{8}{81} Y$ & $\frac{1}{16}$ & $\frac{1}{8}$ & $\frac{1}{2}$ \\
\hline 5. & 2 & $\frac{133}{50}$ & $2 Y\left(\frac{\frac{13}{5}-2}{\frac{13}{5}}\right)^{2}=\frac{18}{169} Y$ & $\frac{1}{8}$ & $\frac{1}{4}$ & $\frac{1}{2}$ \\
\hline 6. & 2 & $\frac{8}{3}$ & $2 Y\left(\frac{\frac{8}{3}-2}{\frac{8}{3}}\right)^{2}=\frac{Y}{8}$ & $\frac{1}{16}$ & $\frac{1}{8}$ & $\frac{1}{2}$ \\
\hline
\end{tabular}

The expected market price and expected domestic profits can be calculated from table 3 leading to $E p=\frac{1399}{700}$ and $\bar{\pi}_{d a}=0.187 Y$. Expected exporting profit $\bar{\pi}_{x a}$ can be calculated easily from the same table as follows:

$$
\begin{aligned}
\bar{\pi}_{x a} & =\frac{1}{16}\left(2 Y\left(\frac{\frac{93}{35}-\frac{53}{20}}{\frac{93}{35}}\right)^{2}+2 Y\left(\frac{\frac{133}{50}-\frac{53}{20}}{\frac{133}{50}}\right)^{2}\right) \\
& =0.00045 Y
\end{aligned}
$$

The change in expected profit is therefore equal to:

$$
\begin{aligned}
d \bar{\pi}_{a} & =\bar{\pi}_{a}\left(2,2, \tau=\frac{53}{20}\right)-\bar{\pi}_{a}\left(2,2, \tau=\frac{8}{3}\right) \\
& =0.187 Y+0.00045 Y-\frac{3}{16} Y \\
& =-0.00040 Y
\end{aligned}
$$

Hence, expected profit falls. Due to the falling trade costs $\pi_{d a}$ decreases more than $\pi_{s x}$ rises. As the free entry condition was marginally satisfied at a tariff of $\tau=8 / 3$, this implies that expected profit net of entry costs becomes negative with $\tau=53 / 20$, the FE in equation (C.2) is violated and the number of entrants drops to one in one of the countries.

Suppose the number of entrants drops to 1 in country a. Expected profit will increase as a result and the new FE is now given by:

$$
\bar{\pi}_{a}(2,2)<f_{e}<\bar{\pi}_{a}(1,2)
$$

We can make new tables with cost draws of firms in country $a$ and $b$ and calculate expected profits and the expected price. Derivations available upon request show that the expected price 
becomes $E p_{a}=\frac{66}{25}$ and $\bar{\pi}_{a}(1,2)=0.490$. Hence, the expected market price increases as a result of lower trade costs, due to the reduction in the number of entrants. This proves Proposition 7 (iii).

Using the value for the expected price $E p_{a}$, expected profit $\bar{\pi}_{a}$ and the number of entrants, the change in welfare in country $a$ from the situation with $\tau=8 / 3, n_{a}^{e}=2, n_{b}^{e}=2$ to the situation with $\tau=53 / 20, n_{a}^{e}=1, n_{b}^{e}=2$ can be calculated as:

$$
\begin{aligned}
d W & =\frac{L+\left(n^{e}-1\right)\left(\bar{\pi}_{a}\left(n_{a}^{e}+1, n_{b}^{e} \mid \tau=53 / 20\right)-f_{e}\right)}{L E(p \mid \tau=53 / 20)}-\frac{L+n^{e}\left(\bar{\pi}_{a}\left(n_{a}^{e}, n_{b}^{e} \mid \tau=8 / 3\right)-f_{e}\right)}{L E(p \mid \tau=8 / 3)} \\
& =\frac{L+\left(\bar{\pi}_{a}(1,2 \mid \tau=53 / 20)-f_{e}\right)}{L E(p \mid \tau=53 / 20)}-\frac{L+2\left(\bar{\pi}_{a}(2,2 \mid \tau=8 / 3)-f_{e}\right)}{L E(p \mid \tau=8 / 3)} \\
& =\frac{L+\left(0.490 L-\frac{3}{16} L\right)}{L \frac{66}{25}}-\frac{L}{L 2} \\
& =-0.00663
\end{aligned}
$$

Hence, in this first example expected welfare falls as a result of lower trade costs and the corresponding change in the number of firms. This proves Proposition 8 (ii). The impact of the price increase is larger than the impact of a larger profit income.

The second example displays a situation where a drop in trade together with a change in the number of entrants generates higher welfare. We work again with two possible cost draws $c_{1}=1, c_{2}=2$, both with probability $1 / 2$. Iceberg trade costs are now equal to $3 / 2$ and sunk entry costs are such that there is one entrant in country $a$ and two entrants in country $b, n_{a}^{e}=1$, $n_{b}^{e}=2$.

$$
\bar{\pi}_{a}(2,2) \leq f_{e} \leq \bar{\pi}_{a}(1,2)
$$

We set sunk entry costs at $f_{e}=0.154 L$. At this level of sunk entry costs the LHS of equation (C.4) is satisfied with equality and expected profits net of entry costs would be equal to zero. Also, a marginal drop in trade costs would lead to an increase in the number of entrants in country $a$ from 1 to 2 .

Suppose trade costs $\tau$ fall from $3 / 2$ to $4 / 3$. Expected profits given two entrants in both countries can then be calculated to be given by $\bar{\pi}_{a}=0.178 L$. Expected profit net of entry costs $f_{e}=0.154 L$ with two entrants would therefore become $\bar{\pi}_{a}-f_{e}=0.0024 L$. Hence, expected profit increases, which leads to violation of the LHS of the FE in equation (C.4). There will be an additional entrant in one of the countries. Suppose there is an additional entrant in country a. Expected profit will fall as a result and the new FE is now given by:

$$
\bar{\pi}_{a}(3,2) \leq f_{e} \leq \bar{\pi}_{a}(2,2)
$$

To find the welfare effect of the change in trade costs together with the induced change in the number of firms, we need to calculate the expected price and expected profit in the old and new situation. It turns out that $E p_{a}=21 / 10$ and $\bar{\pi}_{a}(1,2)=0.290 L$ in the old situation with $\tau=3 / 2, n_{a}^{e}=1$ and $n_{b}^{e}=2$ and $E p_{a}=\frac{1111}{630}$ and $\bar{\pi}_{a}(2,2)=0.178 L$ in the new situation with $\tau=4 / 3$ and $n_{a}^{e}=n_{b}^{e}=2$. Hence, as a result of lower trade costs and an additional entrant, the expected price rises, but expected profit falls. The change in welfare is however positive:

$$
\begin{aligned}
d W & =\frac{L+\left(n^{e}+1\right)\left(\bar{\pi}_{a}\left(n_{a}^{e}+1, n_{b}^{e} \mid \tau=4 / 3\right)-f_{e}\right)}{L E(p \mid \tau=4 / 3)}-\frac{L+n^{e}\left(\bar{\pi}_{a}\left(n_{a}^{e}, n_{b}^{e} \mid \tau=3 / 2\right)-f_{e}\right)}{L E(p \mid \tau=3 / 2)} \\
& =\frac{L+2\left(\bar{\pi}_{a}(2,2 \mid \tau=4 / 3)-f_{e}\right)}{L E(p \mid \tau=4 / 3)}-\frac{L+\left(\bar{\pi}_{a}(1,2 \mid \tau=3 / 2)-f_{e}\right)}{L E(p \mid \tau=3 / 2)} \\
& =\frac{L+2\left(0.178 L-f_{e}\right)}{L \frac{1111}{630}}-\frac{L+\left(0.290 L-f_{e}\right)}{L \frac{21}{10}} \\
& =0.0533
\end{aligned}
$$


So, in this second example the number of entrants increases as a result of lower trade costs, because the increased exporting profits dominate the reduced domestic profits. Welfare rises, as the price reduction has a larger effect than the drop in expected price.

Exporting profit declining in trade costs

Exporting profit of a firm with cost $c$ in country $a$ is defined as:

$$
\pi_{x a}\left(p_{b}, \tau_{a b} c\right)=\sigma Y_{a} P_{u a}^{\sigma-1} \frac{\left(p_{b}-\tau_{a b} c\right)^{2}}{p_{b}^{\sigma+1}}
$$

Log differentiating exporting profit in equation (C.6) with respect to $\tau_{a b}$, we find:

$$
\begin{aligned}
\frac{\partial \ln \pi_{x a}}{\partial \ln \tau_{a b}} & =\frac{2\left(p_{b} \varepsilon_{p_{b}, \tau_{a b}}-\tau_{a b} c\right)}{p_{b}-\tau_{a b} c}-(\sigma+1) \varepsilon_{p_{b}, \tau_{a b}} \\
& =-(\sigma-1) \varepsilon_{p_{b}, \tau_{a b}}-2 \frac{\tau_{a b} c}{p_{b}-\tau_{a b} c}\left(1-\varepsilon_{p_{b}, \tau_{a b}}\right)
\end{aligned}
$$

As $0<\varepsilon_{p_{b}, \tau_{a b}} \leq 1$ from equation (22), we have shown that exporting profit rises with lower $\tau$. 
Table 4: Cost draws, resulting market prices and probabilities with $n_{a}^{e}=2, n_{b}^{e}=2, \tau=8 / 3$

\begin{tabular}{|l|l|l|l|l|l|l|l|}
\hline Draw & $c_{a 1}$ & $c_{a 2}, c_{b 1}, c_{b 2}$ & $p_{a}$ & $\pi_{a}\left(p_{a}, c_{a 1}\right)$ & $P$ & $J\left(p \mid c, n^{e}\right)$ & $f(c)$ \\
\hline 1. & 1 & $1,1,1$ & $\frac{4}{3}$ & $2 Y \frac{\left(\frac{4}{3}-1\right)^{2}}{\frac{4}{3}}=\frac{Y}{8}$ & $\frac{1}{16}$ & $\frac{1}{8}$ & $\frac{1}{2}$ \\
\hline 2. & 1 & $1,1,2$ & $\frac{4}{3}$ & $\frac{Y}{8}$ & $\frac{1}{16}$ & $\frac{1}{8}$ & $\frac{1}{2}$ \\
3. & 1 & $1,2,1$ & $\frac{4}{3}$ & $\frac{Y}{8}$ & $\frac{1}{16}$ & $\frac{1}{8}$ & $\frac{1}{2}$ \\
4. & 1 & $1,2,2$ & $\frac{4}{3}$ & $\frac{Y}{8}$ & $\frac{1}{16}$ & $\frac{1}{8}$ & $\frac{1}{2}$ \\
5. & 1 & $2,1,1$ & 2 & $2 Y \frac{(2-1)^{2}}{2^{2}}=\frac{Y}{2}$ & $\frac{1}{16}$ & $\frac{1}{8}$ & $\frac{1}{2}$ \\
\hline 6. & 1 & $2,1,2$ & 2 & $\frac{Y}{2}$ & $\frac{1}{16}$ & $\frac{1}{8}$ & $\frac{1}{2}$ \\
\hline 7. & 1 & $2,2,1$ & 2 & $\frac{Y}{2}$ & $\frac{1}{16}$ & $\frac{1}{8}$ & $\frac{1}{2}$ \\
\hline 8. & 1 & $2,2,2$ & 2 & $\frac{Y}{2}$ & $\frac{1}{16}$ & $\frac{1}{8}$ & $\frac{1}{2}$ \\
\hline 9. & 2 & $1,1,1$ & 2 & 0 & $\frac{1}{16}$ & $\frac{1}{8}$ & $\frac{1}{2}$ \\
\hline 10. & 2 & $1,1,2$ & 2 & 0 & $\frac{1}{16}$ & $\frac{1}{8}$ & $\frac{1}{2}$ \\
\hline 11. & 2 & $1,2,1$ & 2 & 0 & $\frac{1}{16}$ & $\frac{1}{8}$ & $\frac{1}{2}$ \\
\hline 12. & 2 & $1,2,2$ & 2 & 0 & $\frac{1}{16}$ & $\frac{1}{8}$ & $\frac{1}{2}$ \\
\hline 13. & 2 & $2,1,1$ & $\frac{8}{3}$ & $2 Y\left(\frac{\frac{8}{3}-2}{\frac{8}{3}}\right)^{2}=\frac{Y}{8}$ & $\frac{1}{16}$ & $\frac{1}{8}$ & $\frac{1}{2}$ \\
\hline 14. & 2 & $2,1,2$ & $\frac{8}{3}$ & $\frac{Y}{8}$ & $\frac{1}{16}$ & $\frac{1}{8}$ & $\frac{1}{2}$ \\
\hline 15. & 2 & $2,2,1$ & $\frac{8}{3}$ & $\frac{Y}{8}$ & $\frac{1}{16}$ & $\frac{1}{8}$ & $\frac{1}{2}$ \\
\hline 16. & 2 & $2,2,2$ & $\frac{8}{3}$ & $\frac{Y}{8}$ & $\frac{1}{16}$ & $\frac{1}{8}$ & $\frac{1}{2}$ \\
\hline
\end{tabular}

\section{Supplementary Appendix of Derivations}

This supplementary appendix presents the underlying tables and calculations of the two examples in appendix Appendix C.

First example

Table 4 gives the underlying cost draws, profits and probabilities implying table 2 with cost draws of a single firm, prices, profits and probabilities.

The expected price and profit following from table 4 are given by $E p=2$ and $\bar{\pi}_{d a}=\frac{3}{16} Y$. Expected exporting profit is zero at the prohibititive tariff level of $\tau=8 / 3$. Expected profit minus entry costs can be calculated using equation (40) as follows:

$$
\begin{aligned}
\bar{\pi}_{a} & =\bar{\pi}_{d a}=\left(L+2\left(\bar{\pi}_{a}-f_{e}\right)\right) \frac{3}{16} \\
\frac{5}{8} \bar{\pi}_{a} & =\left(L+2\left(\bar{\pi}-f_{e}\right)\right) \frac{3}{16} \\
\bar{\pi}_{a} & =\frac{3}{10}\left(L-2 f_{e}\right) \\
\bar{\pi}_{a}-f_{e} & =\frac{3}{10}\left(L-\left(2+\frac{10}{3}\right) f_{e}\right) \\
\bar{\pi}_{a}-f_{e} & =\frac{3}{10}\left(L-\frac{16}{3} f_{e}\right)
\end{aligned}
$$

Next, table 5 displays cost draws, price, profit and probabilities when trade costs are reduced to $\tau=2.65=53 / 20$ and the number of entrants is still two in both countries, $n_{a}^{e}=n_{b}^{e}=2$.

The expected price and domestic profit following from table 5 are given by $E p=\frac{1399}{700}$ and $\bar{\pi}_{d a}=0.187 Y$. The expected exporting profit $\bar{\pi}_{x a}$ can be easily calculated from table 5 as 
Table 5: Cost draws, resulting market prices and probabilities with $n_{a}^{e}=2, n_{b}^{e}=2, \tau=53 / 20$

\begin{tabular}{|l|l|l|l|l|l|l|l|}
\hline Draw & $c_{a 1}$ & $c_{a 2}, c_{b 1}, c_{b 2}$ & $p_{a}$ & $\pi_{a}\left(p_{a}, c_{a 1}\right)$ & $P$ & $J\left(p \mid c, n^{e}\right)$ & $f(c)$ \\
\hline 1. & 1 & $1,1,1$ & $\frac{4}{3}$ & $2 Y \frac{\left(\frac{4}{3}-1\right)^{2}}{\frac{4}{3}}=\frac{Y}{8}$ & $\frac{1}{16}$ & $\frac{1}{8}$ & $\frac{1}{2}$ \\
\hline 2. & 1 & $1,1,2$ & $\frac{4}{3}$ & $\frac{Y}{8}$ & $\frac{1}{16}$ & $\frac{1}{8}$ & $\frac{1}{2}$ \\
3. & 1 & $1,2,1$ & $\frac{4}{3}$ & $\frac{Y}{8}$ & $\frac{1}{16}$ & $\frac{1}{8}$ & $\frac{1}{2}$ \\
4. & 1 & $1,2,2$ & $\frac{4}{3}$ & $\frac{Y}{8}$ & $\frac{1}{16}$ & $\frac{1}{8}$ & $\frac{1}{2}$ \\
5. & 1 & $2,1,1$ & 2 & $2 Y \frac{(2-1)^{2}}{2^{2}}=\frac{Y}{2}$ & $\frac{1}{16}$ & $\frac{1}{8}$ & $\frac{1}{2}$ \\
\hline 6. & 1 & $2,1,2$ & 2 & $\frac{Y}{2}$ & $\frac{1}{16}$ & $\frac{1}{8}$ & $\frac{1}{2}$ \\
\hline 7. & 1 & $2,2,1$ & 2 & $\frac{Y}{2}$ & $\frac{1}{16}$ & $\frac{1}{8}$ & $\frac{1}{2}$ \\
\hline 8. & 1 & $2,2,2$ & 2 & $\frac{Y}{2}$ & $\frac{1}{16}$ & $\frac{1}{8}$ & $\frac{1}{2}$ \\
\hline 9. & 2 & $1,1,1$ & 2 & 0 & $\frac{1}{16}$ & $\frac{1}{8}$ & $\frac{1}{2}$ \\
\hline 10. & 2 & $1,1,2$ & 2 & 0 & $\frac{1}{16}$ & $\frac{1}{8}$ & $\frac{1}{2}$ \\
\hline 11. & 2 & $1,2,1$ & 2 & 0 & $\frac{1}{16}$ & $\frac{1}{8}$ & $\frac{1}{16}$ \\
\hline 12. & 2 & $1,2,2$ & 2 & 0 & $\frac{1}{8}$ & $\frac{1}{2}$ \\
\hline 13. & 2 & $2,1,1$ & $\frac{93}{35}$ & $2 Y\left(\frac{\frac{93}{35}-2}{35}\right)^{2}=\frac{1058}{8649} Y$ & $\frac{1}{8}$ & $\frac{1}{2}$ \\
\hline 14. & 2 & $2,1,2$ & $\frac{133}{50}$ & $2 Y\left(\frac{\frac{133}{50}-2}{\frac{133}{50}}\right)^{2}=\frac{2178}{17689} Y$ & $\frac{1}{16}$ & $\frac{1}{8}$ & $\frac{1}{2}$ \\
\hline 15. & 2 & $2,2,1$ & $\frac{133}{50}$ & $\frac{2178}{17689} Y$ & $\frac{1}{16}$ & $\frac{1}{8}$ & $\frac{1}{2}$ \\
\hline 16. & 2 & $2,2,2$ & $\frac{8}{3}$ & $2 Y\left(\frac{\frac{8}{3}-2}{\frac{8}{3}}\right)^{2}=\frac{Y}{8}$ & $\frac{1}{16}$ & $\frac{1}{8}$ & $\frac{1}{2}$ \\
\hline
\end{tabular}

follows:

$$
\begin{aligned}
\bar{\pi}_{x a} & =\frac{1}{16}\left(2 Y\left(\frac{\frac{93}{35}-\frac{53}{20}}{\frac{93}{35}}\right)^{2}+2 Y\left(\frac{\frac{133}{50}-\frac{53}{20}}{\frac{133}{50}}\right)^{2}\right) \\
& =0.000453 Y
\end{aligned}
$$

The change in expected profit as a result of trade costs changed from $\tau=8 / 3$ to $\tau=53 / 20$ is therefore equal to:

$$
\begin{aligned}
d \bar{\pi}_{a} & =\bar{\pi}_{a}\left(2,2, \tau=\frac{53}{20}\right)-\bar{\pi}_{a}\left(2,2, \tau=\frac{8}{3}\right) \\
& =0.187 Y+0.000453 Y-\frac{3}{16} Y \\
& =-0.000047 Y
\end{aligned}
$$

Next, we present tables with domestic and exporting profit in country $a$ and $b$, with trade costs at the reduced level of $\tau=2.65=53 / 20$ and the number of entrants reduced to one in country $a, n_{a}^{e}=1, n_{b}^{e}=2$. For this asymmetric case we have to calculate expected profit in the two countries separately, as the number of entrants is unequal. Table 6 displays cost draws, price, domestic profit in country $a$ and probabilities when trade costs are at the reduced level of $\tau=2.65=53 / 20$ and the number of entrants has also dropped to one in country $a, n_{a}^{e}=1$, $n_{b}^{e}=2$.

The expected price and expected domestic profit following from table 6 are given by $E p_{a}=\frac{66}{25}$ and $\bar{\pi}_{d a}=0.376 Y_{a}$. 
Table 6: Cost draws, resulting market prices and probabilities, expected domestic profit in country $a$ with $n_{a}^{e}=2, n_{b}^{e}=2, \tau=53 / 20$

\begin{tabular}{|l|l|l|l|l|l|l|l|}
\hline Draw & $c_{a 1}$ & $c_{b 1}, c_{b 2}$ & $p_{a}$ & $\pi_{d a}\left(p_{a}, c_{a 1}\right)$ & $P$ & $J\left(p \mid c, n^{e}\right)$ & $f(c)$ \\
\hline 1. & 1 & 1,1 & 2 & $2 Y_{a} \frac{(2-1)^{2}}{2^{2}}=\frac{Y_{a}}{2}$ & $\frac{1}{8}$ & $\frac{1}{4}$ & $\frac{1}{2}$ \\
\hline 2. & 1 & 1,2 & 2 & $\frac{Y_{a}}{2}$ & $\frac{1}{8}$ & $\frac{1}{4}$ & $\frac{1}{2}$ \\
3. & 1 & 2,1 & 2 & $\frac{Y_{a}}{2}$ & $\frac{1}{8}$ & $\frac{1}{4}$ & $\frac{1}{2}$ \\
4. & 1 & 2,2 & 2 & $\frac{Y_{a}}{2}$ & $\frac{1}{8}$ & $\frac{1}{4}$ & $\frac{1}{2}$ \\
\hline 5. & 2 & 1,1 & $\frac{73}{25}$ & $2 Y_{a}\left(\frac{\frac{73}{25}-2}{\frac{73}{25}}\right)^{2}=\frac{1058}{5329} Y_{a}$ & $\frac{1}{8}$ & $\frac{1}{4}$ & $\frac{1}{2}$ \\
\hline 6. & 2 & 1,2 & $\frac{31}{10}$ & $2 Y_{a}\left(\frac{\frac{31}{10}-2}{\frac{31}{10}}\right)^{2}=\frac{242}{961} Y_{a}$ & $\frac{1}{8}$ & $\frac{1}{4}$ & $\frac{1}{2}$ \\
\hline 7. & 2 & 2,1 & $\frac{31}{10}$ & $\frac{242}{961} Y_{a}$ & $\frac{1}{8}$ & $\frac{1}{4}$ & $\frac{1}{2}$ \\
\hline 8. & 2 & 2,2 & 4 & $2 Y_{a}\left(\frac{4-2}{4}\right)^{2}=\frac{Y_{a}}{2}$ & $\frac{1}{8}$ & $\frac{1}{4}$ & $\frac{1}{2}$ \\
\hline
\end{tabular}

Table 7: Cost draws, resulting market prices and probabilities, expected exporting profit in country $a$ with $n_{a}^{e}=2, n_{b}^{e}=2, \tau=53 / 20$

\begin{tabular}{|l|l|l|l|l|l|l|l|}
\hline Draw & $c_{a 1}$ & $c_{b 1}, c_{b 2}$ & $p_{b}$ & $\pi_{x a}\left(p_{b}, c_{a 1}\right)$ & $P$ & $J\left(p \mid c, n^{e}\right)$ & $f(c)$ \\
\hline 1. & 1 & 1,1 & $\frac{4}{3}$ & 0 & $\frac{1}{8}$ & $\frac{1}{4}$ & $\frac{1}{2}$ \\
\hline 2. & 1 & 1,2 & 2 & 0 & $\frac{1}{8}$ & $\frac{1}{4}$ & $\frac{1}{2}$ \\
3. & 1 & 2,1 & 2 & 0 & $\frac{1}{8}$ & $\frac{1}{4}$ & $\frac{1}{2}$ \\
4. & 1 & 2,2 & $\frac{133}{50}$ & $2 Y_{b}\left(\frac{\frac{133}{50}-\frac{53}{20}}{\frac{20}{20}}\right)^{2}=\frac{2}{70225} Y_{b}$ & $\frac{1}{8}$ & $\frac{1}{4}$ & $\frac{1}{2}$ \\
\hline 5. & 2 & 1,1 & $\frac{4}{3}$ & 0 & $\frac{1}{8}$ & $\frac{1}{4}$ & $\frac{1}{2}$ \\
\hline 6. & 2 & 1,2 & 2 & 0 & $\frac{1}{8}$ & $\frac{1}{4}$ & $\frac{1}{2}$ \\
\hline 7. & 2 & 2,1 & 2 & 0 & $\frac{1}{8}$ & $\frac{1}{4}$ & $\frac{1}{2}$ \\
\hline 8. & 2 & 2,2 & $\frac{8}{3}$ & 0 & $\frac{1}{8}$ & $\frac{1}{4}$ & $\frac{1}{2}$ \\
\hline
\end{tabular}

Table 7 displays cost draws, price, exporting profit of country $a$ and probabilities when trade costs are at the reduced level of $\tau=2.65=53 / 20$ and the number of entrants has also dropped to one in country $a, n_{a}^{e}=1, n_{b}^{e}=2$.

Expected exporting profit following from table 7 is given by $\bar{\pi}_{x a}=\frac{1}{280900} Y_{b}$

Table 8 displays cost draws, price, domestic profit in country $b$ and probabilities when trade costs are at the reduced level of $\tau=2.65=53 / 20$ and the number of entrants has also dropped to one in country $a, n_{a}^{e}=1, n_{b}^{e}=2$.

Expected domestic profit following from table 8 is given by $\bar{\pi}_{d b}=0.187 Y_{b}$.

Table 9 displays cost draws, price, exporting profit in country $b$ and probabilities when trade costs are at the reduced level of $\tau=2.65=53 / 20$ and the number of entrants has also dropped to one in country $a, n_{a}^{e}=1, n_{b}^{e}=2$.

Expected exporting profit following from table 9 is given by $\bar{\pi}_{x b}=0.00741 Y_{a}$. Total expected profit of firms from country $a$ and $b$ can be calculated as follows:

$$
\begin{aligned}
\bar{\pi}_{a} & =\bar{\pi}_{d a}+\bar{\pi}_{x a} \\
& =0.376 Y_{a}+\frac{1}{280900} Y_{b} \\
\bar{\pi}_{b} & =\bar{\pi}_{d b}+\bar{\pi}_{x b} \\
& =0.187 Y_{b}+0.00741 Y_{a}
\end{aligned}
$$


Table 8: Cost draws, resulting market prices and probabilities, expected domestic profit in country $b$ with $n_{a}^{e}=2, n_{b}^{e}=2, \tau=53 / 20$

\begin{tabular}{|l|l|l|l|l|l|l|l|}
\hline Draw & $c_{b 1}$ & $c_{b 2}, c_{a 1}$ & $p_{b}$ & $\pi_{d b}\left(p_{b}, c_{b 1}\right)$ & $P$ & $J\left(p \mid c, n^{e}\right)$ & $f(c)$ \\
\hline 1. & 1 & 1,1 & $\frac{4}{3}$ & $2 Y_{b} \frac{\left(\frac{4}{3}-1\right)^{2}}{\frac{4}{3}}=\frac{Y_{b}}{8}$ & $\frac{1}{8}$ & $\frac{1}{4}$ & $\frac{1}{2}$ \\
\hline 2. & 1 & 1,2 & $\frac{4}{3}$ & $\frac{Y_{b}}{8}$ & $\frac{1}{8}$ & $\frac{1}{4}$ & $\frac{1}{2}$ \\
3. & 1 & 2,1 & 2 & $2 Y_{b} \frac{(2-1)^{2}}{2^{2}}=\frac{Y_{b}}{2}$ & $\frac{1}{8}$ & $\frac{1}{4}$ & $\frac{1}{2}$ \\
4. & 1 & 2,2 & 2 & $\frac{Y_{b}}{2}$ & $\frac{1}{8}$ & $\frac{1}{4}$ & $\frac{1}{2}$ \\
\hline 5. & 2 & 1,1 & 2 & 0 & $\frac{1}{8}$ & $\frac{1}{4}$ & $\frac{1}{2}$ \\
\hline 6. & 2 & 1,2 & 2 & 0 & $\frac{1}{8}$ & $\frac{1}{4}$ & $\frac{1}{2}$ \\
\hline 7. & 2 & 2,1 & $\frac{133}{50}$ & $2 Y_{b}\left(\frac{\frac{133}{50}-2}{\frac{133}{50}}\right)^{2}=\frac{2178}{17689} Y_{b}$ & $\frac{1}{8}$ & $\frac{1}{4}$ & $\frac{1}{2}$ \\
\hline 8. & 2 & 2,2 & $\frac{8}{3}$ & $2 Y_{b}\left(\frac{\frac{8}{3}-2}{\frac{8}{3}}\right)^{2}=\frac{Y_{b}}{8}$ & $\frac{1}{8}$ & $\frac{1}{4}$ & $\frac{1}{2}$ \\
\hline
\end{tabular}

Table 9: Cost draws, resulting market prices and probabilities, expected exporting profit in country $b$ with $n_{a}^{e}=2, n_{b}^{e}=2, \tau=53 / 20$

\begin{tabular}{|l|l|l|l|l|l|l|l|}
\hline Draw & $c_{b 1}$ & $c_{b 2}, c_{a 1}$ & $p_{a}$ & $\pi_{x b}\left(p_{a}, c_{a 1}\right)$ & $P$ & $J\left(p \mid c, n^{e}\right)$ & $f(c)$ \\
\hline 1. & 1 & 1,1 & 2 & 0 & $\frac{1}{8}$ & $\frac{1}{4}$ & $\frac{1}{2}$ \\
\hline 2. & 1 & 1,2 & $\frac{68}{25}$ & $2 Y_{a}\left(\frac{\frac{73}{25}-\frac{53}{20}}{\frac{73}{25}}\right)^{2}=\frac{729}{42632} Y_{a}$ & $\frac{1}{8}$ & $\frac{1}{4}$ & $\frac{1}{2}$ \\
3. & 1 & 2,1 & 2 & 0 & $\frac{1}{8}$ & $\frac{1}{4}$ & $\frac{1}{2}$ \\
4. & 1 & 2,2 & $\frac{31}{10}$ & $2 Y_{a}\left(\frac{\frac{31}{10}-\frac{53}{20}}{\frac{31}{10}}\right)^{2}=\frac{81}{1922} Y_{a}$ & $\frac{1}{8}$ & $\frac{1}{4}$ & $\frac{1}{2}$ \\
\hline 5. & 2 & 1,1 & 2 & 0 & $\frac{1}{8}$ & $\frac{1}{4}$ & $\frac{1}{2}$ \\
\hline 6. & 2 & 1,2 & $\frac{31}{10}$ & 0 & $\frac{1}{8}$ & $\frac{1}{4}$ & $\frac{1}{2}$ \\
\hline 7. & 2 & 2,1 & 2 & 0 & $\frac{1}{8}$ & $\frac{1}{4}$ & $\frac{1}{2}$ \\
\hline 8. & 2 & 2,2 & 4 & 0 & $\frac{1}{8}$ & $\frac{1}{4}$ & $\frac{1}{2}$ \\
\hline
\end{tabular}


Table 10: Cost draws, resulting market prices and probabilities, expected domestic profit in country $a$ with $n_{a}^{e}=2, n_{b}^{e}=2, \tau=3 / 2$

\begin{tabular}{|l|l|l|l|l|l|l|l|}
\hline Draw & $c_{a 1}$ & $c_{a 2}, c_{b 1}, c_{b 2}$ & $p_{a}$ & $\pi_{d a}\left(p_{a}, c_{a 1}\right)$ & $P$ & $J\left(p_{a} \mid c_{a 1}, n_{a}^{e}, n_{b}^{e}\right)$ & $f\left(c_{a 1}\right)$ \\
\hline 1. & 1 & $1,1,1$ & $\frac{4}{3}$ & $2 Y\left(\frac{\frac{4}{3}-1}{\frac{4}{3}}\right)^{2}=\frac{Y}{8}$ & $\frac{1}{16}$ & $\frac{1}{8}$ & $\frac{1}{2}$ \\
\hline 2. & 1 & $1,1,2$ & $\frac{4}{3}$ & $\frac{Y}{8}$ & $\frac{1}{16}$ & $\frac{1}{8}$ & $\frac{1}{2}$ \\
3. & 1 & $1,2,1$ & $\frac{4}{3}$ & $\frac{Y}{8}$ & $\frac{1}{16}$ & $\frac{1}{8}$ & $\frac{1}{2}$ \\
4. & 1 & $1,2,2$ & $\frac{4}{3}$ & $\frac{Y}{8}$ & $\frac{1}{16}$ & $\frac{1}{8}$ & $\frac{1}{2}$ \\
5. & 1 & $2,1,1$ & $\frac{8}{5}$ & $2 Y\left(\frac{\frac{8}{5}-1}{\frac{8}{5}}\right)^{2}=\frac{9}{32} Y$ & $\frac{1}{16}$ & $\frac{1}{8}$ & $\frac{1}{2}$ \\
\hline 6. & 1 & $2,1,2$ & $\frac{5}{3}$ & $2 Y\left(\frac{\frac{5}{3}-1}{\frac{5}{3}}\right)^{2}=\frac{8}{25} Y$ & $\frac{1}{16}$ & $\frac{1}{8}$ & $\frac{1}{2}$ \\
\hline 7. & 1 & $2,2,1$ & $\frac{5}{3}$ & $\frac{8}{25} Y$ & $\frac{1}{16}$ & $\frac{1}{8}$ & $\frac{1}{2}$ \\
\hline 8. & 1 & $2,2,2$ & 2 & $2 Y\left(\frac{2-1}{2}\right)^{2}=\frac{Y}{2}$ & $\frac{1}{16}$ & $\frac{1}{8}$ & $\frac{1}{2}$ \\
\hline 9. & 2 & $1,1,1$ & $\frac{8}{5}$ & 0 & $\frac{1}{16}$ & $\frac{1}{8}$ & $\frac{1}{2}$ \\
\hline 10. & 2 & $1,1,2$ & $\frac{5}{3}$ & 0 & $\frac{1}{16}$ & $\frac{1}{8}$ & $\frac{1}{2}$ \\
\hline 11. & 2 & $1,2,1$ & $\frac{5}{3}$ & 0 & $\frac{1}{16}$ & $\frac{1}{8}$ & $\frac{1}{2}$ \\
\hline 12. & 2 & $1,2,2$ & 2 & 0 & $\frac{1}{16}$ & $\frac{1}{8}$ & $\frac{1}{2}$ \\
\hline 13. & 2 & $2,1,1$ & 2 & 0 & $\frac{1}{16}$ & $\frac{1}{8}$ & $\frac{1}{2}$ \\
\hline 14. & 2 & $2,1,2$ & $\frac{11}{5}$ & $2 Y\left(\frac{\frac{11}{5}-2}{\frac{11}{5}}\right)^{2}=\frac{2}{121} Y$ & $\frac{1}{16}$ & $\frac{1}{8}$ & $\frac{1}{2}$ \\
\hline 15. & 2 & $2,2,1$ & $\frac{11}{5}$ & $\frac{2}{121} Y$ & $\frac{1}{16}$ & $\frac{1}{8}$ & $\frac{1}{2}$ \\
\hline 16. & 2 & $2,2,2$ & $\frac{8}{3}$ & $2 Y\left(\frac{\frac{8}{3}-2}{\frac{8}{3}}\right)^{2}=\frac{Y}{8}$ & $\frac{1}{16}$ & $\frac{1}{8}$ & $\frac{1}{2}$ \\
\hline
\end{tabular}

Combining equations (S.1) and (S.2) and substituting equations (40) and $f_{e}=\frac{3}{16} L$ leads to:

$$
\begin{aligned}
& \bar{\pi}_{a}=0.376\left(L+\left(\bar{\pi}_{a}-f_{e}\right)\right)+\frac{1}{280900}\left(L+2\left(\bar{\pi}_{b}-f_{e}\right)\right) \\
& \bar{\pi}_{b}=0.187\left(L+2\left(\bar{\pi}_{b}-f_{e}\right)\right)+0.00741\left(L+\left(\bar{\pi}_{a}-f_{e}\right)\right)
\end{aligned}
$$

Solving for $\bar{\pi}_{a}$ and $\bar{\pi}_{b}$, we find $\bar{\pi}_{a}=0.490 L$ and $\bar{\pi}_{b}=0.203 L$.

We can now calculate the change in welfare in country $a$ from the situation with $\tau=8 / 3$, $n_{a}^{e}=2, n_{b}^{e}=2$ to the situation with $\tau=53 / 20, n_{a}^{e}=1, n_{b}^{e}=2$ :

$$
\begin{aligned}
d W & =\frac{L+\left(n^{e}-1\right)\left(\bar{\pi}_{a}\left(n_{a}^{e}+1, n_{b}^{e}\right)-f_{e}\right)}{L E p^{\prime}}-\frac{L+n^{e}\left(\bar{\pi}_{a}\left(n_{a}^{e}, n_{b}^{e}\right)-f_{e}\right)}{L E p} \\
& =\frac{L+\left(\bar{\pi}_{a}(1,2)-f_{e}\right)}{L E p_{a}}-\frac{L+2\left(\bar{\pi}_{a}(2,2)-f_{e}\right)}{L E p_{a}} \\
& =\frac{L+\left(0.490 L-\frac{3}{16} L\right)}{L \frac{66}{25}}-\frac{L}{L 2} \\
& =-0.00663
\end{aligned}
$$

\section{Second example}

We start with the calculation of the value of sunk entry costs that leads to satisfaction on the LHS of the FE in equation (C.4). Therefore, table 10 displays cost draws, price, domestic profit in country $a$ and probabilities when trade costs are equal to $\tau=3 / 2$ and the number of entrants is equal to 2 in both countries, $n_{a}^{e}=n_{b}^{e}=2$

Expected domestic profit following from table 10 is thus equal to $\bar{\pi}_{d a}=0.130 Y$. Next, we have to calculate exporting profit. Thus, table 11 displays cost draws, price, exporting profit in 
Table 11: Cost draws, resulting market prices and probabilities, expected exporting profit in country $a$ with $n_{a}^{e}=2, n_{b}^{e}=2, \tau=3 / 2$

\begin{tabular}{|l|l|l|l|l|l|l|l|}
\hline Draw & $c_{a 1}$ & $c_{a 2}, c_{b 1}, c_{b 2}$ & $p_{b}$ & $\pi_{x a}\left(p_{b}, c_{a 1}\right)$ & $P$ & $J\left(p_{b} \mid c_{a 1}, n_{a}^{e}, n_{b}^{e}\right)$ & $f\left(c_{a 1}\right)$ \\
\hline 1. & 1 & $1,1,1$ & $\frac{4}{3}$ & 0 & $\frac{1}{16}$ & $\frac{1}{8}$ & $\frac{1}{2}$ \\
\hline 2. & 1 & $1,1,2$ & $\frac{8}{5}$ & $2 Y\left(\frac{\frac{16}{10}-\frac{15}{10}}{\frac{16}{10}}\right)^{2}=\frac{Y}{128}$ & $\frac{1}{16}$ & $\frac{1}{8}$ & $\frac{1}{2}$ \\
3. & 1 & $1,2,1$ & $\frac{8}{5}$ & $\frac{Y}{128}$ & $\frac{1}{16}$ & $\frac{1}{8}$ & $\frac{1}{2}$ \\
4. & 1 & $1,2,2$ & 2 & $2 Y\left(\frac{2-\frac{3}{2}}{2}\right)^{2}=\frac{Y}{8}$ & $\frac{1}{16}$ & $\frac{1}{8}$ & $\frac{1}{2}$ \\
5. & 1 & $2,1,1$ & $\frac{4}{3}$ & 0 & $\frac{1}{16}$ & $\frac{1}{8}$ & $\frac{1}{2}$ \\
\hline 6. & 1 & $2,1,2$ & $\frac{5}{3}$ & $2 Y\left(\frac{\frac{10}{6}-\frac{9}{6}}{\frac{10}{6}}\right)^{2}=\frac{Y}{50}$ & $\frac{1}{16}$ & $\frac{1}{8}$ & $\frac{1}{2}$ \\
\hline 7. & 1 & $2,2,1$ & $\frac{5}{3}$ & $\frac{Y}{50}$ & $\frac{1}{16}$ & $\frac{1}{8}$ & $\frac{1}{2}$ \\
\hline 8. & 1 & $2,2,2$ & $\frac{11}{5}$ & $2 Y\left(\frac{22}{10}-\frac{15}{\frac{22}{10}}\right)^{2}=\frac{49}{244} Y$ & $\frac{1}{16}$ & $\frac{1}{8}$ & $\frac{1}{2}$ \\
\hline 9. & 2 & $1,1,1$ & $\frac{4}{3}$ & 0 & $\frac{1}{16}$ & $\frac{1}{8}$ & $\frac{1}{2}$ \\
\hline 10. & 2 & $1,1,2$ & $\frac{5}{3}$ & 0 & $\frac{1}{16}$ & $\frac{1}{8}$ & $\frac{1}{2}$ \\
\hline 11. & 2 & $1,2,1$ & $\frac{5}{3}$ & 0 & $\frac{1}{16}$ & $\frac{1}{8}$ & $\frac{1}{2}$ \\
\hline 12. & 2 & $1,2,2$ & $\frac{11}{5}$ & 0 & $\frac{1}{16}$ & $\frac{1}{8}$ & $\frac{1}{2}$ \\
\hline 13. & 2 & $2,1,1$ & $\frac{4}{3}$ & 0 & $\frac{1}{16}$ & $\frac{1}{8}$ & $\frac{1}{2}$ \\
\hline 14. & 2 & $2,1,2$ & 2 & 0 & $\frac{1}{16}$ & $\frac{1}{8}$ & $\frac{1}{2}$ \\
\hline 15. & 2 & $2,2,1$ & 2 & 0 & $\frac{1}{16}$ & $\frac{1}{8}$ & $\frac{1}{2}$ \\
\hline 16. & 2 & $2,2,2$ & $\frac{8}{3}$ & 0 & $\frac{1}{2}$ \\
\hline
\end{tabular}

country $a$ and probabilities when trade costs are equal to $\tau=3 / 2$ and the number of entrants is equal to 2 in both countries, $n_{a}^{e}=n_{b}^{e}=2$.

Expected exporting profit following from table 11 is given by $\bar{\pi}_{x a}=0.0238 Y$. We only have to calculate expected profit for one of the two countries, as the number of entrants is two in both countries and hence values are equal in both countries. Total expected profit in country $a$ is equal to:

$$
\begin{aligned}
\bar{\pi}_{a} & =\bar{\pi}_{d a}+\bar{\pi}_{x a} \\
& =0.130 Y+0.0238 Y \\
& =0.154 Y
\end{aligned}
$$

Substituting equation (40) and solving for $\bar{\pi}_{a}$ gives:

$$
\begin{aligned}
& \bar{\pi}_{a}=0.154\left(L+2\left(\bar{\pi}_{a}-f_{e}\right)\right) \\
& \bar{\pi}_{a}=0.154\left(L-2 f_{e}\right)
\end{aligned}
$$

Therefore expected profits net of $f_{e}$ is equal to:

$$
\bar{\pi}_{a}-f_{e}=0.154\left(L-6.502 f_{e}\right)
$$

The FE is thus marginally satisfied if:

$$
f_{e}=0.154 L
$$

Next, we calculate expected profit when iceberg trade costs fall to $\tau=\frac{4}{3}$ to check whether the FE in equation (C.4) will be violated leading to additional entry. Table 12 displays cost draws, 
Table 12: Cost draws, resulting market prices and probabilities, expected domestic profit in country $a$ with $n_{a}^{e}=2, n_{b}^{e}=2, \tau=4 / 3$

\begin{tabular}{|l|l|l|l|l|l|l|l|}
\hline Draw & $c_{a 1}$ & $c_{a 2}, c_{b 1}, c_{b 2}$ & $p_{a}$ & $\pi_{d a}\left(p_{a}, c_{a 1}\right)$ & $P$ & $J\left(p_{a} \mid c_{a 1}, n_{a}^{e}, n_{b}^{e}\right)$ & $f\left(c_{a 1}\right)$ \\
\hline 1. & 1 & $1,1,1$ & $\frac{4}{3}$ & $2 Y\left(\frac{\frac{4}{3}-1}{\frac{4}{3}}\right)^{2}=\frac{Y}{8}$ & $\frac{1}{16}$ & $\frac{1}{8}$ & $\frac{1}{2}$ \\
\hline 2. & 1 & $1,1,2$ & $\frac{4}{3}$ & $\frac{Y}{8}$ & $\frac{1}{16}$ & $\frac{1}{8}$ & $\frac{1}{2}$ \\
3. & 1 & $1,2,1$ & $\frac{4}{3}$ & $\frac{Y}{8}$ & $\frac{1}{16}$ & $\frac{1}{8}$ & $\frac{1}{2}$ \\
4. & 1 & $1,2,2$ & $\frac{4}{3}$ & $\frac{Y}{8}$ & $\frac{1}{16}$ & $\frac{1}{8}$ & $\frac{1}{2}$ \\
5. & 1 & $2,1,1$ & $\frac{34}{21}$ & $2 Y\left(\frac{\frac{34}{21}-1}{\frac{34}{21}}\right)^{2}=\frac{169}{578} Y$ & $\frac{1}{16}$ & $\frac{1}{8}$ & $\frac{1}{2}$ \\
\hline 6. & 1 & $2,1,2$ & $\frac{26}{15}$ & $2 Y\left(\frac{\frac{26}{15}-1}{\frac{26}{15}}\right)^{2}=\frac{121}{338} Y$ & $\frac{1}{16}$ & $\frac{1}{8}$ & $\frac{1}{2}$ \\
\hline 7. & 1 & $2,2,1$ & $\frac{26}{15}$ & $\frac{121}{338} Y$ & $\frac{1}{16}$ & $\frac{1}{8}$ & $\frac{1}{2}$ \\
\hline 8. & 1 & $2,2,2$ & 2 & $2 Y\left(\frac{2-1}{2}\right)^{2}=\frac{Y}{2}$ & $\frac{1}{16}$ & $\frac{1}{8}$ & $\frac{1}{2}$ \\
\hline 9. & 2 & $1,1,1$ & $\frac{34}{21}$ & 0 & $\frac{1}{16}$ & $\frac{1}{8}$ & $\frac{1}{2}$ \\
\hline 10. & 2 & $1,1,2$ & $\frac{26}{15}$ & 0 & $\frac{1}{16}$ & $\frac{1}{8}$ & $\frac{1}{2}$ \\
\hline 11. & 2 & $1,2,1$ & $\frac{26}{15}$ & 0 & $\frac{1}{16}$ & $\frac{1}{8}$ & $\frac{1}{2}$ \\
\hline 12. & 2 & $1,2,2$ & 2 & 0 & $\frac{1}{16}$ & $\frac{1}{8}$ & $\frac{1}{2}$ \\
\hline 13. & 2 & $2,1,1$ & $\frac{16}{9}$ & 0 & $\frac{1}{16}$ & $\frac{1}{8}$ & $\frac{1}{2}$ \\
\hline 14. & 2 & $2,1,2$ & $\frac{32}{15}$ & $2 Y\left(\frac{1}{16}\right)^{2}=\frac{1}{128} Y$ & $\frac{1}{16}$ & $\frac{1}{8}$ & $\frac{1}{2}$ \\
\hline 15. & 2 & $2,2,1$ & $\frac{32}{15}$ & $\frac{1}{128} Y$ & $\frac{1}{16}$ & $\frac{1}{8}$ & $\frac{1}{2}$ \\
\hline 16. & 2 & $2,2,2$ & $\frac{8}{3}$ & $2 Y\left(\frac{\frac{8}{3}-2}{\frac{8}{3}}\right)^{2}=\frac{Y}{8}$ & $\frac{1}{16}$ & $\frac{1}{8}$ & $\frac{1}{2}$ \\
\hline
\end{tabular}

price, domestic profit in country $a$ and probabilities when trade costs are equal to $\tau=4 / 3$ and the number of entrants is equal to 2 in both countries, $n_{a}^{e}=n_{b}^{e}=2$ :

The expected price and expected domestic profit following from table 12 are given by $E p_{a}=$ $\frac{1111}{630}$ and $\bar{\pi}_{d a}=0.134 Y$.

Next, we calculate expected exporting profit and table 13 displays cost draws, price, exporting profit in country $a$ and probabilities when trade costs are equal to $\tau=4 / 3$ and the number of entrants is equal to 2 in both countries, $n_{a}^{e}=n_{b}^{e}=2$.

Expected exporting profit following from table 13 is equal to $\bar{\pi}_{x a}=0.0356 Y$.

Total expected profit when $\tau=4 / 3$ and $n_{a}^{e}=n_{b}^{e}$ is thus equal to:

$$
\begin{aligned}
\bar{\pi}_{a} & =\bar{\pi}_{d a}+\bar{\pi}_{x a} \\
& =0.134 Y+0.0356 Y \\
& =0.170 Y
\end{aligned}
$$

Using equation (40) and solving for $\bar{\pi}_{a}$ generates:

$$
\begin{aligned}
& \bar{\pi}_{a}=0.170\left(L+2\left(\bar{\pi}_{a}-f_{e}\right)\right) \\
& \bar{\pi}_{a}=0.257\left(L-2 f_{e}\right)
\end{aligned}
$$

The change in expected profit from $\tau=3 / 2$ to $\tau=4 / 3$ is therefore:

$$
\begin{aligned}
\bar{\pi}_{a}\left(2 \mid \tau=\frac{4}{3}\right)-\bar{\pi}_{a}\left(2 \mid \tau=\frac{3}{2}\right) & =0.0352\left(L-2 f_{e}\right) \\
& =0.0244 L
\end{aligned}
$$


Table 13: Cost draws, resulting market prices and probabilities, expected exporting profit in country $a$ with $n_{a}^{e}=2, n_{b}^{e}=2, \tau=4 / 3$

\begin{tabular}{|l|l|l|l|l|l|l|l|}
\hline Draw & $c_{a 1}$ & $c_{a 2}, c_{b 1}, c_{b 2}$ & $p_{b}$ & $\pi_{x a}\left(p_{b}, c_{a 1}\right)$ & $P$ & $J\left(p_{b} \mid c_{a 1}, n_{a}^{e}, n_{b}^{e}\right)$ & $f\left(c_{a 1}\right)$ \\
\hline 1. & 1 & $1,1,1$ & $\frac{4}{3}$ & 0 & $\frac{1}{16}$ & $\frac{1}{8}$ & $\frac{1}{2}$ \\
\hline 2. & 1 & $1,1,2$ & $\frac{34}{21}$ & $2 Y\left(\frac{6}{34}\right)^{2}=\frac{18}{289} Y$ & $\frac{1}{16}$ & $\frac{1}{8}$ & $\frac{1}{2}$ \\
3. & 1 & $1,2,1$ & $\frac{34}{21}$ & $\frac{18}{289} Y$ & $\frac{1}{16}$ & $\frac{1}{8}$ & $\frac{1}{2}$ \\
4. & 1 & $1,2,2$ & $\frac{16}{9}$ & $2 Y\left(\frac{\frac{4}{9}}{\frac{16}{9}}\right)^{2}=\frac{Y}{8}$ & $\frac{1}{16}$ & $\frac{1}{8}$ & $\frac{1}{2}$ \\
5. & 1 & $2,1,1$ & $\frac{4}{3}$ & 0 & $\frac{1}{16}$ & $\frac{1}{8}$ & $\frac{1}{2}$ \\
\hline 6. & 1 & $2,1,2$ & $\frac{26}{15}$ & $2 Y\left(\frac{6}{26}\right)^{2}=\frac{18}{169} Y$ & $\frac{1}{16}$ & $\frac{1}{8}$ & $\frac{1}{2}$ \\
\hline 7. & 1 & $2,2,1$ & $\frac{26}{15}$ & $\frac{18}{169} Y$ & $\frac{1}{16}$ & $\frac{1}{8}$ & $\frac{1}{2}$ \\
\hline 8. & 1 & $2,2,2$ & $\frac{32}{15}$ & $2 Y\left(\frac{3}{8}\right)^{2}=\frac{9}{32} Y$ & $\frac{1}{16}$ & $\frac{1}{8}$ & $\frac{1}{2}$ \\
\hline 9. & 2 & $1,1,1$ & $\frac{4}{3}$ & 0 & $\frac{1}{16}$ & $\frac{1}{8}$ & $\frac{1}{2}$ \\
\hline 10. & 2 & $1,1,2$ & $\frac{26}{15}$ & 0 & $\frac{1}{16}$ & $\frac{1}{8}$ & $\frac{1}{2}$ \\
\hline 11. & 2 & $1,2,1$ & $\frac{26}{15}$ & 0 & $\frac{1}{16}$ & $\frac{1}{8}$ & $\frac{1}{2}$ \\
\hline 12. & 2 & $1,2,2$ & $\frac{32}{15}$ & 0 & $\frac{1}{16}$ & $\frac{1}{8}$ & $\frac{1}{2}$ \\
\hline 13. & 2 & $2,1,1$ & $\frac{4}{3}$ & 0 & $\frac{1}{16}$ & $\frac{1}{8}$ & $\frac{1}{2}$ \\
\hline 14. & 2 & $2,1,2$ & 2 & 0 & $\frac{1}{16}$ & $\frac{1}{8}$ & $\frac{1}{2}$ \\
\hline 15. & 2 & $2,2,1$ & 2 & 0 & $\frac{1}{16}$ & $\frac{1}{8}$ & $\frac{1}{2}$ \\
\hline 16. & 2 & $2,2,2$ & $\frac{8}{3}$ & 0 & $\frac{1}{16}$ & $\frac{1}{8}$ & $\frac{1}{2}$ \\
\hline
\end{tabular}

An identical result is found when the expected profit net of entry costs is calculated in the new situation only as expected profit net of entry costs in the old situation was equal to zero:

$$
\begin{aligned}
\bar{\pi}_{a}\left(2 \mid \tau=\frac{4}{3}\right)-f_{e} & =0.257\left(L-2 f_{e}\right)-f_{e} \\
& =0.0244 L
\end{aligned}
$$

Hence, the two calculations lead to identical results because of the following equality:

$$
\begin{aligned}
\bar{\pi}_{a}\left(2 \mid \tau=\frac{4}{3}\right)-\bar{\pi}_{a}\left(2 \mid \tau=\frac{3}{2}\right) & =\left(\bar{\pi}_{a}\left(2 \mid \tau=\frac{4}{3}\right)-f_{e}\right)-\left(\bar{\pi}_{a}\left(2 \mid \tau=\frac{3}{2}\right)-f_{e}\right) \\
& =\bar{\pi}_{a}\left(2 \mid \tau=\frac{4}{3}\right)-f_{e}
\end{aligned}
$$

Hence, expected profit increases, which leads to violation of the FE. There will be an additional entrant in one of the countries.

Consider the situation before the change in the number of entrants, so with one entrant in country $a$, two entrants in country $b$ and $\tau=3 / 2$.

To compare welfare in the old and new situation, we also have to calculate the expected price and expected profit in the old situation with $\tau=3 / 2, n_{a}^{e}=1$ and $n_{b}^{e}=2$. Therefore, table 14 displays cost draws, price, domestic profit in country $a$ and probabilities when trade costs are equal to $\tau=3 / 2$ and $n_{a}^{e}=1$ and $n_{b}^{e}=2$ :

The expected price and expected profit following from table 14 are given by $E p_{a}=\frac{21}{10}$ and $\bar{\pi}_{d a}=0.223 Y_{a}$.

Next, table 15 displays cost draws, price, exporting profit in country $a$ and probabilities when trade costs are equal to $\tau=3 / 2$ and $n_{a}^{e}=1$ and $n_{b}^{e}=2$ :

Expected exporting profit following from table 15 is given by $\bar{\pi}_{x a}=0.0303 Y_{b}$. 
Table 14: Cost draws, resulting market prices and probabilities, expected domestic profit in country $a$ with $n_{a}^{e}=1, n_{b}^{e}=2, \tau=3 / 2$

\begin{tabular}{|l|l|l|l|l|l|l|l|}
\hline Draw & $c_{a 1}$ & $c_{b 1}, c_{b 2}$ & $p_{a}$ & $\pi_{d a}\left(p_{a}, c_{a 1}\right)$ & $P$ & $J\left(p \mid c, n^{e}\right)$ & $f(c)$ \\
\hline 1. & 1 & 1,1 & $\frac{8}{5}$ & $2 Y_{a}\left(\frac{\frac{8}{5}-1}{\frac{8}{5}}\right)^{2}=\frac{9}{32} Y_{a}$ & $\frac{1}{8}$ & $\frac{1}{4}$ & $\frac{1}{2}$ \\
\hline 2. & 1 & 1,2 & $\frac{5}{3}$ & $2 Y_{a}\left(\frac{\frac{5}{3}-1}{\frac{5}{3}}\right)^{2}=\frac{8}{25} Y_{a}$ & $\frac{1}{8}$ & $\frac{1}{4}$ & $\frac{1}{2}$ \\
3. & 1 & 2,1 & $\frac{5}{3}$ & $2 Y_{a}\left(\frac{\frac{5}{3}-1}{\frac{5}{3}}\right)^{2}=\frac{8}{25} Y_{a}$ & $\frac{1}{8}$ & $\frac{1}{4}$ & $\frac{1}{2}$ \\
4. & 1 & 2,2 & 2 & $2 Y_{a}\left(\frac{2-1}{2}\right)^{2}=\frac{1}{2} Y_{a}$ & $\frac{1}{8}$ & $\frac{1}{4}$ & $\frac{1}{2}$ \\
\hline 5. & 2 & 1,1 & 2 & 0 & $\frac{1}{8}$ & $\frac{1}{4}$ & $\frac{1}{2}$ \\
\hline 6. & 2 & 1,2 & $\frac{7}{3}$ & $2 Y_{a}\left(\frac{\frac{7}{3}-2}{\frac{7}{3}}\right)^{2}=\frac{2}{49} Y_{a}$ & $\frac{1}{8}$ & $\frac{1}{4}$ & $\frac{1}{2}$ \\
\hline 7. & 2 & 2,1 & $\frac{7}{3}$ & $2 Y_{a}\left(\frac{\frac{7}{3}-2}{\frac{7}{3}}\right)^{2}=\frac{2}{49} Y_{a}$ & $\frac{1}{8}$ & $\frac{1}{4}$ & $\frac{1}{2}$ \\
\hline 8. & 2 & 2,2 & $\frac{16}{5}$ & $2 Y_{a}\left(\frac{\frac{16}{5}-2}{\frac{16}{5}}\right)^{2}=\frac{9}{32} Y_{a}$ & $\frac{1}{8}$ & $\frac{1}{4}$ & $\frac{1}{2}$ \\
\hline
\end{tabular}

Table 15: Cost draws, resulting market prices and probabilities, expected exporting profit in country $a$ with $n_{a}^{e}=1, n_{b}^{e}=2, \tau=3 / 2$

\begin{tabular}{|l|l|l|l|l|l|l|l|}
\hline Draw & $c_{a 1}$ & $c_{b 1}, c_{b 2}$ & $p_{b}$ & $\pi_{x a}\left(p_{b}, c_{a 1}\right)$ & $P$ & $J\left(p \mid c, n^{e}\right)$ & $f(c)$ \\
\hline 1. & 1 & 1,1 & $\frac{4}{3}$ & 0 & $\frac{1}{8}$ & $\frac{1}{4}$ & $\frac{1}{2}$ \\
\hline 2. & 1 & 1,2 & $\frac{5}{3}$ & $2 Y_{b}\left(\frac{\frac{5}{3}-\frac{3}{2}}{\frac{5}{3}}\right)^{2}=\frac{1}{50} Y_{b}$ & $\frac{1}{8}$ & $\frac{1}{4}$ & $\frac{1}{2}$ \\
3. & 1 & 2,1 & $\frac{5}{3}$ & $2 Y_{b}\left(\frac{\frac{5}{3}-\frac{3}{2}}{\frac{5}{3}}\right)^{2}=\frac{1}{50} Y_{b}$ & $\frac{1}{8}$ & $\frac{1}{4}$ & $\frac{1}{2}$ \\
4. & 1 & 2,2 & $\frac{11}{5}$ & $2 Y_{b}\left(\frac{\frac{11}{5}-\frac{3}{2}}{\frac{11}{5}}\right)^{2}=\frac{49}{242} Y_{b}$ & $\frac{1}{8}$ & $\frac{1}{4}$ & $\frac{1}{2}$ \\
\hline 5. & 2 & 1,1 & $\frac{4}{3}$ & 0 & $\frac{1}{8}$ & $\frac{1}{4}$ & $\frac{1}{2}$ \\
\hline 6. & 2 & 1,2 & 2 & 0 & $\frac{1}{8}$ & $\frac{1}{4}$ & $\frac{1}{2}$ \\
\hline 7. & 2 & 2,1 & 2 & 0 & $\frac{1}{8}$ & $\frac{1}{4}$ & $\frac{1}{2}$ \\
\hline 8. & 2 & 2,2 & $\frac{8}{3}$ & 0 & $\frac{1}{8}$ & $\frac{1}{4}$ & $\frac{1}{2}$ \\
\hline
\end{tabular}


Table 16: Cost draws, resulting market prices and probabilities, expected domestic profit in country $b$ with $n_{a}^{e}=1, n_{b}^{e}=2, \tau=3 / 2$

\begin{tabular}{|l|l|l|l|l|l|l|l|}
\hline Draw & $c_{b 1}$ & $c_{b 2}, c_{a 1}$ & $p_{b}$ & $\pi_{d b}\left(p_{b}, c_{b 1}\right)$ & $P$ & $J\left(p \mid c, n^{e}\right)$ & $f(c)$ \\
\hline 1. & 1 & 1,1 & $\frac{4}{3}$ & $2 Y_{b}\left(\frac{\frac{4}{3}-1}{\frac{4}{3}}\right)^{2}=\frac{1}{8} Y_{b}$ & $\frac{1}{8}$ & $\frac{1}{4}$ & $\frac{1}{2}$ \\
\hline 2. & 1 & 1,2 & $\frac{4}{3}$ & $2 Y_{b}\left(\frac{\frac{4}{3}-1}{\frac{4}{3}}\right)^{2}=\frac{1}{8} Y_{b}$ & $\frac{1}{8}$ & $\frac{1}{4}$ & $\frac{1}{2}$ \\
3. & 1 & 2,1 & $\frac{5}{3}$ & $2 Y_{b}\left(\frac{\frac{5}{3}-1}{\frac{5}{3}}\right)^{2}=\frac{8}{25} Y_{b}$ & $\frac{1}{8}$ & $\frac{1}{4}$ & $\frac{1}{2}$ \\
4. & 1 & 2,2 & 2 & $2 Y_{b}\left(\frac{2-1}{2}\right)^{2}=\frac{1}{2} Y_{b}$ & $\frac{1}{8}$ & $\frac{1}{4}$ & $\frac{1}{2}$ \\
\hline 5. & 2 & 1,1 & $\frac{5}{3}$ & 0 & $\frac{1}{8}$ & $\frac{1}{4}$ & $\frac{1}{2}$ \\
\hline 6. & 2 & 1,2 & 2 & 0 & $\frac{1}{8}$ & $\frac{1}{4}$ & $\frac{1}{2}$ \\
\hline 7. & 2 & 2,1 & $\frac{11}{5}$ & $2 Y_{b}\left(\frac{\frac{11}{5}-2}{\frac{11}{5}}\right)^{2}=\frac{2}{121} Y_{b}$ & $\frac{1}{8}$ & $\frac{1}{4}$ & $\frac{1}{2}$ \\
\hline 8. & 2 & 2,2 & $\frac{8}{3}$ & $2 Y_{b}\left(\frac{\frac{8}{3}-2}{\frac{8}{3}}\right)^{2}=\frac{1}{8} Y_{b}$ & $\frac{1}{8}$ & $\frac{1}{4}$ & $\frac{1}{2}$ \\
\hline
\end{tabular}

Table 17: Cost draws, resulting market prices and probabilities, expected exporting profit in country $a$ with $n_{a}^{e}=1, n_{b}^{e}=2, \tau=3 / 2$

\begin{tabular}{|l|l|l|l|l|l|l|l|}
\hline Draw & $c_{b 1}$ & $c_{b 2}, c_{a 1}$ & $p_{a}$ & $\pi_{x b}\left(p_{a}, c_{b 1}\right)$ & $P$ & $J\left(p \mid c, n^{e}\right)$ & $f(c)$ \\
\hline 1. & 1 & 1,1 & $\frac{8}{5}$ & $2 Y_{a}\left(\frac{\frac{8}{5}-\frac{3}{2}}{\frac{8}{5}}\right)^{2}=\frac{1}{128} Y_{a}$ & $\frac{1}{8}$ & $\frac{1}{4}$ & $\frac{1}{2}$ \\
\hline 2. & 1 & 1,2 & 2 & $2 Y_{a}\left(\frac{2-\frac{3}{2}}{2}\right)^{2}=\frac{1}{8} Y_{a}$ & $\frac{1}{8}$ & $\frac{1}{4}$ & $\frac{1}{2}$ \\
3. & 1 & 2,1 & $\frac{5}{3}$ & $2 Y_{a}\left(\frac{\frac{5}{3}-\frac{3}{2}}{\frac{5}{3}}\right)^{2}=\frac{1}{50} Y_{a}$ & $\frac{1}{8}$ & $\frac{1}{4}$ & $\frac{1}{2}$ \\
4. & 1 & 2,2 & $\frac{7}{3}$ & $2 Y_{a}\left(\frac{\frac{7}{3}-\frac{3}{2}}{2}\right)^{2}=\frac{25}{72} Y_{a}$ & $\frac{1}{8}$ & $\frac{1}{4}$ & $\frac{1}{2}$ \\
\hline 5. & 2 & 1,1 & $\frac{5}{3}$ & 0 & $\frac{1}{8}$ & $\frac{1}{4}$ & $\frac{1}{2}$ \\
\hline 6. & 2 & 1,2 & $\frac{7}{3}$ & 0 & $\frac{1}{8}$ & $\frac{1}{4}$ & $\frac{1}{2}$ \\
\hline 7. & 2 & 2,1 & 2 & 0 & $\frac{1}{8}$ & $\frac{1}{4}$ & $\frac{1}{2}$ \\
\hline 8. & 2 & 2,2 & $\frac{16}{5}$ & $2 Y_{a}\left(\frac{\frac{16}{5}-3}{\frac{16}{5}}\right)^{2}=\frac{1}{128} Y_{a}$ & $\frac{1}{8}$ & $\frac{1}{4}$ & $\frac{1}{2}$ \\
\hline
\end{tabular}

Total expected profit of a firm from country $a$ is thus equal to:

$$
\begin{aligned}
\bar{\pi}_{a} & =\bar{\pi}_{d a}+\bar{\pi}_{x a} \\
& =0.223 Y_{a}+0.0303 Y_{b}
\end{aligned}
$$

Next, we also have to calculate expected profit in country $b$, as the case is asymmetric. Table 16 displays cost draws, price, domestic profit in country $b$ and probabilities when trade costs are equal to $\tau=3 / 2$ and $n_{a}^{e}=1$ and $n_{b}^{e}=2$ :

Expected domestic profit in country $b$ following from table 16 is therefore given by $\bar{\pi}_{d b}=$ $0.151 Y_{b}$.

Finally, table 17 displays cost draws, price, exporting profit in country $b$ and probabilities when trade costs are equal to $\tau=3 / 2$ and $n_{a}^{e}=1$ and $n_{b}^{e}=2$ :

Expected exporting profit of a firm from country $b$ following from table 17 is given by $\bar{\pi}_{x b}=0.0634 Y_{a}$.

Total expected profit of a firm from country $b$ is thus equal to:

$$
\begin{aligned}
\bar{\pi}_{b} & =\bar{\pi}_{d b}+\bar{\pi}_{x b} \\
& =0.151 Y_{b}+0.0634 Y_{a}
\end{aligned}
$$


Combining the expressions for profit in country $a$ and $b$, equations (S.4) and (S.5), substituting equations (40) and (S.3), leads to:

$$
\begin{aligned}
& \bar{\pi}_{a}=0.223\left(L+\left(\bar{\pi}_{a}-f_{e}\right)\right)+0.0303\left(L+2\left(\bar{\pi}_{b}-f_{e}\right)\right) \\
& \bar{\pi}_{b}=0.151\left(L+2\left(\bar{\pi}_{b}-f_{e}\right)\right)+0.0634\left(L+\left(\bar{\pi}_{a}-f_{e}\right)\right)
\end{aligned}
$$

Solving for $\bar{\pi}_{a}$ and $\bar{\pi}_{b}$, we find $\bar{\pi}_{a}=0.290 L$ and $\bar{\pi}_{b}=0.254 L$.

We can now calculate the change in welfare in country $a$ from the situation with $\tau=3 / 2$, $n_{a}^{e}=1, n_{b}^{e}=2$ to the situation with $\tau=4 / 3, n_{a}^{e}=2, n_{b}^{e}=2$ :

$$
\begin{aligned}
d W & =\frac{L+\left(n^{e}+1\right)\left(\bar{\pi}_{a}\left(n_{a}^{e}+1, n_{b}^{e}\right)-f_{e}\right)}{L E p^{\prime}}-\frac{L+n^{e}\left(\bar{\pi}_{a}\left(n_{a}^{e}, n_{b}^{e}\right)-f_{e}\right)}{L E p} \\
& =\frac{L+2\left(\bar{\pi}_{a}(2,2 \mid \tau=4 / 3)-f_{e}\right)}{L E(p \mid \tau=4 / 3)}-\frac{L+\left(\bar{\pi}_{a}(1,2 \mid \tau=3 / 2)-f_{e}\right)}{L E(p \mid \tau=3 / 2)} \\
& =\frac{L+2\left(0.178-f_{e}\right)}{L \frac{1111}{630}}-\frac{L+\left(0.290 L-f_{e}\right)}{L \frac{21}{10}} \\
& =0.0533
\end{aligned}
$$

